\title{
The Ins and Outs of Mycobacterium tuberculosis Protein Export
}

\author{
Lauren S. Ligon ${ }^{\mathrm{a}}$, Jennifer D. Hayden ${ }^{\mathrm{a}}$, and Miriam Braunstein ${ }^{\mathrm{a},{ }^{*}}$ \\ Lauren S. Ligon: lauren_ligon@med.unc.edu; Jennifer D. Hayden: jenny_hayden@med.unc.edu \\ aDepartment of Microbiology and Immunology, University of North Carolina at Chapel Hill, CB \# \\ 7290, Chapel Hill, NC 27599, USA
}

\section{Abstract}

Mycobacterium tuberculosis is an important pathogen that infects approximately one third of the world's population and kills almost two million people annually. An important aspect of $M$. tuberculosis physiology and pathogenesis is its ability to export proteins into and across the thick mycobacterial cell envelope, where they are ideally positioned to interact with the host. In addition to the specific proteins that are exported by M. tuberculosis, the systems through which these proteins are exported represent potential targets for future drug development. M. tuberculosis possesses two well-known and conserved export systems: the housekeeping Sec pathway and the Tat pathway. In addition, M. tuberculosis possesses specialized export systems including the accessory SecA2 pathway and five ESX pathways. Here we review the current understanding of each of these export systems, with a focus on M. tuberculosis, and discuss the contribution of each system to disease and physiology.

\section{Keywords}

secretion; Sec; SecA2; Tat; ESX

\section{Introduction}

Mycobacterium tuberculosis is the causative agent of the disease tuberculosis, which the World Health Organization estimates kills almost 2 million people every year ${ }^{1}$. Although tuberculosis is treatable, it requires a long antibiotic regimen that is expensive and difficult, especially for people in the developing world. Furthermore, multidrug resistant (MDR) and extensively drug resistant (XDR) M. tuberculosis make treatment even more problematic and novel drugs are desperately needed to combat this disease.

Because of their importance to virulence and bacterial viability, the exported proteins of $M$. tuberculosis and their respective protein export systems can be considered potential drug targets (recently reviewed in ${ }^{2}$ ). Many exported proteins, which we define as including proteins in the cell envelope of M. tuberculosis and proteins secreted by M. tuberculosis, interact with the host and are crucial for causing disease. Without its systems for transporting these proteins across the cytoplasmic membrane and to their final destination,

\footnotetext{
(c) 2011 Elsevier Ltd. All rights reserved.

*To whom correspondence should be addressed: Miriam Braunstein Phone: 919-966-5051, Fax: 919-962-8103, miriam_braunstein@med.unc.edu, Mailing Address: University of North Carolina at Chapel Hill, CB \# 7290, Chapel Hill, NC 27599. Publisher's Disclaimer: This is a PDF file of an unedited manuscript that has been accepted for publication. As a service to our customers we are providing this early version of the manuscript. The manuscript will undergo copyediting, typesetting, and review of the resulting proof before it is published in its final citable form. Please note that during the production process errors may be discovered which could affect the content, and all legal disclaimers that apply to the journal pertain.
} 
M. tuberculosis cannot deliver effector proteins that are necessary for virulence.

Furthermore, some M. tuberculosis protein export systems are essential. Although there are currently no approved drugs that target bacterial protein export pathways, inhibitors of such systems in other bacteria have been identified ${ }^{3-6}$.

In M. tuberculosis, there are two highly conserved protein export systems that are responsible for the majority of protein export: the Sec and Tat export pathways. $M$. tuberculosis also possesses specialized protein export systems dedicated to the export of a more limited set of proteins: the accessory SecA2 export pathway and ESX pathways. ESX pathways are also referred to as Type VII secretion systems. Interestingly, both of these specialized protein export systems were first identified in M. tuberculosis but later found to also exist in some other bacteria. Here we review the current state of research on the protein export systems of mycobacteria with an emphasis on studies performed in M. tuberculosis.

\section{Housekeeping Sec Export System}

\section{Introduction}

The Sec system is highly conserved and present in all bacteria, and it acts as the primary route for exporting proteins to the cytoplasmic membrane and beyond. Because many of the proteins exported by the Sec system perform vital functions that require proper export, the Sec pathway is essential for bacterial viability (Table 1). In addition, many bacterial proteins with roles in virulence are exported by the Sec system ${ }^{7}$. The current understanding of Sec export comes from extensive study in Escherichia coli (for recent reviews see ${ }^{8,9}$ ). While Sec export functions in essentially the same manner in all bacteria in which it has been studied, only a few aspects of this system have been directly investigated in mycobacteria.

\section{Exported Proteins and Targeting}

The Sec system exports proteins across the cytoplasmic membrane post-translationally. Proteins exported by the Sec system, termed preproteins or precursors, are synthesized with an N-terminal signal peptide that is important for targeting the protein for export. Following export, the signal peptide is cleaved to generate the mature protein. Sec signal peptides consist of a positively charged $\mathrm{N}$-terminus, a hydrophobic central domain, and an uncharged polar C-terminus containing the cleavage site ${ }^{9}$. Some Sec-exported proteins are lipoproteins, and in these cases the C-terminal end of the signal peptide contains a lipobox motif with a conserved cysteine that is the site of lipid attachment ${ }^{10}$. Sec signal peptides and lipoprotein signal peptides can be predicted using the bioinformatic programs PSORTb v3.0 ${ }^{11}$, SignalP v3.0 ${ }^{12}$, and LipoP v1.0 ${ }^{13}$.

Proteins must be in an unfolded state to be exported by the Sec system. In many Gramnegative bacteria there is a $\mathrm{Sec}$ export chaperone, $\mathrm{SecB}$, that binds preproteins, maintains them in an unfolded state, and delivers them to SecA - a central component of the Sec system discussed below. However, not all preproteins of Gram-negative bacteria require $\mathrm{SecB}$, and Gram-positive bacteria lack a SecB ortholog ${ }^{14}$. In the absence of SecB, it is thought that other proteins fulfill the role of export chaperone. In M. tuberculosis, Bordes et al. recently identified Rv1957 as a SecB-like protein ${ }^{15}$. Rv1957 prevents proteolysis and aggregation of M. tuberculosis HigA, a presumed cytoplasmic protein that is part of the $M$. tuberculosis HigBA toxin-antitoxin system. These activities are consistent with Rv1957 being a chaperone. However, there is currently no evidence that Rv1957 functions as a chaperone for protein export and it is possible that the function of Rv1957 is restricted to the HigBA system. 


\section{System Components and Mechanism}

SecA is a multifunctional component of the Sec export system that works with the heterotrimeric SecYEG membrane channel to export proteins across the cytoplasmic membrane. SecA recognizes and binds to the signal peptide, as well as portions of the mature domain, of preproteins ${ }^{16,17}$. SecA is also an ATPase that harnesses energy from multiple rounds of ATP binding and hydrolysis to "push" preproteins through the SecYEG channel ${ }^{18,19}$. The proton motive force can also contribute to Sec export, but is not absolutely required ${ }^{19}$.

Mycobacteria and some Gram-positive bacteria have two SecA proteins, each with distinct functions. The primary housekeeping SecA, that functions like SecA of E. coli, is referred to as SecA1, while the accessory SecA is referred to as SecA2 (see later section for SecA2 discussion). SecA1 is predicted to be essential in M. tuberculosis ${ }^{20,21}$ and proven to be essential in the model mycobacterium M. smegmatis ${ }^{22}$. Because secAl deletion mutants are not viable, conditional silencing has been used to study SecA1 function. As would be expected for a housekeeping SecA, depletion of SecA1 in M. smegmatis causes both growth inhibition and reduced export of a test protein with a Sec signal peptide ${ }^{23,24} \cdot M$. tuberculosis SecA1 is also a demonstrated ATPase ${ }^{25}$, and the X-ray crystal structure of $M$. tuberculosis SecA1 is similar to other bacterial SecA structures ${ }^{26}$.

The SecYEG complex provides the channel through which proteins travel across the cytoplasmic membrane ${ }^{27}$ and together with SecA it forms the "translocase," which is the minimum apparatus needed to reconstitute efficient Sec export in vitro ${ }^{28}$. SecY is a polytopic membrane protein and the largest component of the SecYEG complex, forming the pore in the membrane through which proteins pass during export. SecE is suggested to act as a "clamp" to stabilize SecY ${ }^{29}$. SecG improves efficiency of protein export ${ }^{30}$. Additional Sec components that improve export efficiency are SecD, SecF, and YajC ${ }^{31}$.

Once a protein has been exported across the membrane, the signal peptide is removed by one of two signal peptidases - the Type I signal peptidase LepB, or the Type II signal peptidase LspA ${ }^{32}$. LspA acts specifically on lipoprotein signal peptides. The $M$. tuberculosis LspA has been studied and confirmed to function in lipoprotein signal peptide cleavage ${ }^{33}$. Furthermore, an $l s p A$ mutant of $M$. tuberculosis is attenuated in macrophage and mouse models of infection, demonstrating the importance of correctly exported lipoproteins for M. tuberculosis virulence ${ }^{33}$.

In addition to the process described above for exporting proteins completely across the cytoplasmic membrane, the SecYEG channel is also used for a significantly different process - co-translational insertion of integral membrane proteins into the cytoplasmic membrane (for a recent review, see ${ }^{34}$ ). In this process, transmembrane domains of nascent integral membrane proteins are recognized by the signal recognition particle SRP during translation. SRP then delivers the nascent integral membrane protein to the SRP receptor Fts Y, which in turn passes the protein to SecYEG for co-translational insertion into the membrane. SecY contains a "lateral gate" which is believed to allow transmembrane domains of integral membrane proteins to pass sideways out of the SecYEG channel and into the membrane, with the help of the YidC protein ${ }^{35,36}$. While not generally required for integral membrane protein insertion, the SecA protein does assist in the case of integral membrane proteins with large hydrophilic domains ${ }^{37}$. Integral membrane proteins can be predicted using the bioinformatic program TMHMM v2.0 ${ }^{38}$, which searches for transmembrane domains. 


\section{Contribution to Disease and Physiology}

Because the Sec system performs the bulk of protein export, many Sec-exported proteins are important for both $M$. tuberculosis viability and virulence. Several M. tuberculosis proteins proven to function in virulence contain Sec signal peptides ${ }^{39,40}$. Also, as mentioned above, the importance of LspA demonstrates that Sec-exported lipoproteins are important for $M$. tuberculosis virulence ${ }^{33}$. In fact, several lipoproteins with Sec signal peptides are known to be important for M. tuberculosis virulence, including $\mathrm{LpqH}(19 \mathrm{kD}){ }^{41}, \mathrm{LppX}^{42}$, and $\mathrm{LprG}^{43}$. While SecYEG is homologous to the Sec61 complex found in eukaryotic cells, there is no eukaryotic homolog of SecA. The lack of SecA in mammalian cells, combined with the critical importance of SecA1 for both viability and virulence in bacteria, makes SecA1 a compelling potential drug target (as reviewed in ${ }^{2}$ ).

\section{Model, Summary, and Future Questions}

At this point, the studies of SecA1 and LspA are the only ones to directly investigate housekeeping Sec export in mycobacteria $22-26,33,44$. However, the data from these studies, combined with the presence of Sec component orthologues (Table 1) and exported proteins with Sec signal peptides in M. tuberculosis, is consistent with the housekeeping Sec system of mycobacteria functioning as described in other bacteria (Figure 1). In this case, preproteins with $\mathrm{N}$-terminal signal peptides are recognized by SecA1, which interacts with the SecYEG channel complex to form the translocase. SecA1 performs repeated cycles of ATP hydrolysis, pushing segments of the preprotein through the SecYEG channel. Signal peptides are removed by a LepB or LspA signal peptidase, and mature exported proteins fold into their final conformations.

In the future it will be important to expand our understanding of the Sec export system in mycobacteria. For example, nothing is currently known about mycobacterial chaperone(s) involved in Sec export. Also, the process of inserting integral membrane proteins into the mycobacterial cytoplasmic membrane is a topic that has so far received no research attention.

\section{Accessory SecA2 Export System}

\section{Introduction}

All mycobacteria are unusual in having two SecA proteins. In contrast to SecA1, SecA2 is non-essential and secA2 deletion mutants have been constructed in several mycobacteria, including M. tuberculosis ${ }^{45}$ and M. smegmatis ${ }^{22}$. SecA2 functions in protein export, but its role appears limited to a much smaller subset of proteins than those exported by SecA1. $\mathrm{SecA} 2$ is necessary for the full virulence of $M$. tuberculosis 45,46 , suggesting that one or more of the proteins it exports are important in pathogenesis. Accessory SecA2 export has been studied directly in mycobacteria; however, there is still much that is unknown.

\section{Exported Proteins and Targeting}

Comparative 2D-PAGE analysis of exported proteins from wild-type and secA2 deletion mutant strains has been used to identify proteins that require SecA2 for their export 45,47 . Only a small number of proteins are identified in these studies, and they include examples both with and without signal peptides. In $M$. smegmatis, cell wall proteins were analyzed by 2D-PAGE, identifying Msmeg1704 and Msmeg1712 as proteins exported by the SecA2 system ${ }^{47}$. These proteins share many similarities - both are lipoproteins, contain lipoprotein Sec signal peptides ${ }^{13}$, and are predicted sugar-binding proteins. While direct homologues of Msmeg1704 and Msmeg1712 are not found in M. tuberculosis, similar sugar-binding lipoproteins are present, although they have yet to be evaluated for SecA2-dependence. The SecA2-dependent proteins with signal peptides are currently indistinguishable from proteins 
exported by the housekeeping Sec export system, and experimental evidence shows the signal peptide $i s$ required for export of Msmeg1712 47.

In M. tuberculosis, proteins exported into the culture media (culture filtrates) were analyzed by $2 \mathrm{D}-\mathrm{PAGE}{ }^{45}$. Among the very few proteins identified was the antioxidant enzyme SodA (superoxide dismutase). SodA does not have a signal peptide, but its dependence on SecA2 for export is confirmed by western blot and SodA activity assay ${ }^{45,48}$. Given the role of SodA in detoxifying oxygen radicals, the export of $M$. tuberculosis KatG (catalase), another antioxidant enzyme, was directly evaluated for SecA2-dependence. Like SodA, KatG lacks a signal peptide and is dependent on SecA2 for export 45 .

\section{System Components and Mechanism}

Accessory SecA2 proteins are found in all mycobacteria and some Gram-positive bacteria (for an extensive review of SecA2 export, see ${ }^{49}$ ). Several SecA2 export systems include a $\mathrm{SecY} 2$ protein. Referred to as SecA2/Y2 systems, these systems seem to be dedicated to exporting a single large protein that is heavily glycosylated prior to export ${ }^{50-52}$. In contrast, there is no SecY2 in mycobacteria and the system is referred to as a SecA2-only system. Listeria monocytogenes also has a SecA2-only system. A notable similarity between the $L$. monocytogenes and mycobacterial SecA2 systems is that both are reported to export proteins with signal peptides as well as proteins without signal peptides ${ }^{53,54}$. In L. monocytogenes, this includes export of MnSOD (manganese superoxide dismutase), which lacks a signal peptide $^{54}$.

SecA 2 has been directly studied in both $M$. tuberculosis and M. smegmatis. Importantly, complementation experiments show that SecA2 of M. tuberculosis and $M$. smegmatis can substitute for one another to complement secA2 deletion mutant phenotypes ${ }^{24}$. Because these cross-species complementation experiments demonstrate that the SecA2 proteins of $M$. tuberculosis and $M$. smegmatis can carry out the same functions, M. smegmatis has been used as a model for studying the mechanism of mycobacterial SecA2-dependent export.

SecA2 exhibits several similarities to the housekeeping SecA1 protein. SecA1 and SecA2 proteins are present in equivalent amounts in $M$. tuberculosis, and both proteins have proven ATPase activity ${ }^{25}$. Like housekeeping SecA proteins, ATP hydrolysis is also required for SecA2 function in both M. tuberculosis 25 and M. smegmatis 24 .

There are also several differences between SecA1 and SecA2. SecA2 is smaller than SecA1 because it lacks the C-terminal linker region, which in $E$. coli has been implicated in binding to phospholipids, SecB, and zinc ${ }^{55-57}$. SecA2 also differs from SecA1 in how it localizes within the bacterium. Like E. coli SecA, SecA1 is evenly distributed between soluble and cell envelope fractions, but SecA2 is found predominantly in the cytosol-containing soluble fraction ${ }^{24}$. Most importantly, it is clear that SecA1 and SecA2 have independent functions. Even when SecA2 is overexpressed, SecA1 cannot be deleted, indicating that SecA2 cannot substitute for SecA1. Similarly, overexpression of SecA1 does not rescue the phenotypes of a secA2 deletion mutant 22 .

Given that there is no accessory SecY or obvious alternate export channel to work with SecA2 in mycobacteria, it seems likely that SecA2 functions with the help of some or all of the housekeeping Sec export system. To address this possibility, export of the SecA2dependent protein Msmeg1712 was assessed following depletion of SecA1 in M. smegmatis. In the absence of SecA1, export of Msmeg1712 was found to be significantly compromised $^{24}$. The simplest interpretation of this result is that the SecA2 export system needs the housekeeping SecA1 to function. However, the possibility that SecA1 depletion has an indirect effect on SecA2 export cannot currently be ruled out. 


\section{Contribution to Disease and Physiology}

The M. tuberculosis secA2 mutant is attenuated for growth in both macrophages ${ }^{46}$ and the mouse model of tuberculosis infection ${ }^{45}$. These results indicate that the SecA2 system exports proteins important for M. tuberculosis virulence. The fact that both SodA and KatG are dependent on SecA2 for export suggests that the SecA2 system may protect $M$. tuberculosis from the oxidative burst of macrophages. Yet, the secA2 mutant is still attenuated for growth in phox $^{-/-}$macrophages, which cannot produce an oxidative burst ${ }^{46}$. While this result does not exclude a role for SecA2 in resisting oxygen radicals during infection, it does reveal the existence of other roles for the SecA2 system in promoting virulence. During macrophage infection, the M. tuberculosis secA2 mutant induces increased release of proinflammatory cytokines ${ }^{46}$ and increased apoptosis ${ }^{48}$, as compared to wildtype M. tuberculosis. Thus, the SecA2 system may block innate immune responses to enable $M$. tuberculosis growth in macrophages.

\section{Model, Summary, and Future Questions}

More research is needed to elucidate the details of SecA2-dependent export. However the studies conducted so far, particularly those using M. smegmatis, help build a model for this system (Figure 1). SecA2 recognizes a small subset of proteins that are normally not compatible with Sec export, and uses its ATPase activity to assist in their export. It seems most likely that SecA2 works with components of the housekeeping Sec export system, either by delivering proteins to $\mathrm{Sec} \mathrm{A} 1$ or by actively participating in exporting proteins through the SecYEG channel. It remains possible, however, that other unknown components are required in addition to or in lieu of the housekeeping Sec components.

Many important questions remain. For the SecA2-dependent proteins with signal peptides, it is not known what distinguishes them from proteins exported by the housekeeping Sec system, or why these SecA2-dependent proteins cannot be exported by the housekeeping Sec system alone. Interestingly, it appears that the signal peptide of M. smegmatis SecA2dependent proteins does not impart the requirement for SecA2 in their export (Feltcher, M., Gibbons, H., Ligon, L., Braunstein, M., unpublished results). The fact that some SecA2dependent proteins do not have signal peptides adds an additional layer of complexity to understanding this system. It is possible that both proteins with signal peptides and proteins without signal peptides are directly exported by the SecA2 export system. Conversely, the SecA2-dependence of proteins without signal peptides may be an indirect effect. For example, it is possible that the SecA2 system exports an unidentified protein containing a signal peptide, which in turn participates in the export of proteins lacking signal peptides via another pathway. Finally, it is likely that more SecA2-dependent proteins exist and remain to be identified, including $M$. tuberculosis proteins containing signal peptides. Important future goals are to identify additional proteins exported by the SecA2 system and understand the role this export system plays in the pathogenesis of M. tuberculosis.

\section{Tat Export System}

\section{Introduction}

Twin-arginine translocase (Tat) export systems exist in both Gram-negative and Grampositive bacteria, but unlike Sec systems, they are not present in all bacteria ${ }^{58}$. When Tat export systems are found in bacterial pathogens, they are frequently responsible for exporting virulence factors, and thus contribute to pathogenesis ${ }^{59}$. In M. tuberculosis, the Tat system plays a role in both virulence and drug resistance, and it is also essential for viability ${ }^{60}$. The current understanding of Tat export comes from studies in E. coli (for a recent review see ${ }^{61}$ ). 


\section{Exported Proteins and Targeting}

Similar to the Sec system, the Tat system exports proteins across the cytoplasmic membrane in a post-translational manner, and proteins exported by the Tat pathway are synthesized as preproteins with an N-terminal signal peptide. Like Sec signal peptides, Tat signal peptides consist of a positively charged $\mathrm{N}$-terminus, a hydrophobic central domain, and an uncharged polar C-terminus containing a cleavage site. Tat signal peptides are distinguished from Sec signal peptides by the presence of a Tat motif that contains twin-arginine residues at the junction of the charged domain and the hydrophobic domain. The Tat motif is reported as S/ T-R-R-X-F-L-K ${ }^{62}$, or more generically as R-R-X- $\Phi-\Phi(\Phi=$ hydrophobic). Substitution of the twin-arginines with other residues prevents export of most Tat-dependent proteins, but the twin-arginines are not an absolute requirement, as there are examples of both natural ${ }^{63-66}$ and artificial ${ }^{67,68}$ Tat-dependent proteins that have only one arginine.

Several bioinformatic programs are available for predicting Tat signal peptides: TatFind v1.4 ${ }^{69}$, TatP v1.0 ${ }^{70}$, TIGR01409 ${ }^{71}$, and PRED-TAT ${ }^{72}$. However, the list of predicted $M$. tuberculosis Tat signal peptides varies widely between programs ${ }^{64}$. Given the differing predictions of these programs, mycobacterial Tat signal peptides must be identified experimentally. A genetic reporter system utilizing the Tat-exported $M$. tuberculosis $\beta$ lactamase $(\mathrm{BlaC})$ is useful for this purpose ${ }^{63,64}$. $\beta$-lactamases must be exported to confer resistance to $\beta$-lactam antibiotics, and $M$. tuberculosis $\mathrm{BlaC}$ must be exported by the Tat pathway to function. When a truncated $\mathrm{BlaC}$ (lacking its endogenous signal peptide) is fused to a protein containing a functional Tat signal peptide, $\mathrm{BlaC}$ reports on export of the fusion protein by conferring $\beta$-lactam resistance ${ }^{73}$. Using the BlaC reporter, 18 M. tuberculosis proteins are shown to have functional Tat signal peptides (Table 2). M. tuberculosis likely has additional Tat-exported proteins, and more study is needed to obtain a complete list. Examination of the proven Tat signal peptides shows that $M$. tuberculosis uses a very similar Tat motif ( $\Phi-\Sigma$-R-R-X- $\Phi-\Phi, \Sigma=$ small amino acid) to that defined previously.

In addition to a Tat signal peptide, a second requirement for Tat-dependent proteins is that they be folded prior to export. Thus, structural features of the mature domain of a protein are also critical in directing a protein for Tat export. Unfolded or misfolded Tat-dependent proteins are generally unacceptable for export, suggesting the Tat export system has a "proofreading" ability that restricts export to properly folded proteins ${ }^{74,75}$.

\section{System Components and Mechanism}

As is the case in E. coli, mycobacterial Tat export systems consist of three proteins: TatA, TatB, and TatC 60,73,76. TatA and TatB are small homologous proteins, each containing a single transmembrane domain. TatC is a larger protein containing 6 transmembrane domains ${ }^{77}$.

TatB and TatC form a complex that contains the binding site for Tat preproteins ${ }^{78,79}$. After a preprotein binds to TatBC, TatA is recruited to the complex ${ }^{79}$. Tat $\mathrm{A}$ is generally believed to form the export channel ${ }^{61}$ and is found in homo-oligomers of varying size ${ }^{80,81}$, which may give the Tat system the flexibility to export folded proteins of different size and shape. Energy for Tat export is provided by the proton motive force ${ }^{79,82}$. Following export, Tat preproteins undergo signal peptide cleavage by LepB, the type I signal peptidase ${ }^{83}$. Although it has yet to be proven, it is presumed that the signal peptides of Tat-exported lipoproteins ${ }^{84}$ are cleaved by LspA, the type II signal peptidase.

\section{Contribution to Disease and Physiology}

In M. tuberculosis, the Tat export system is essential. The tat $A$, tatB, and tat $C$ genes cannot be deleted unless an extra copy of these genes is provided on a plasmid ${ }^{60}$. This essentiality 
of the M. tuberculosis Tat system is unusual; only one other organism, Sinorhizobium meliloti, is reported to have an essential Tat export system ${ }^{85}$. In fact, even the M. smegmatis Tat system is not essential, although $\operatorname{tat} A, \operatorname{tat} B$, and $\operatorname{tat} C$ deletion mutants do grow slowly in vitro ${ }^{73,76}$. The reason for the essentiality of the M. tuberculosis Tat pathway is not known.

The Tat export systems of mycobacteria also contribute to drug resistance. Mycobacteria are naturally resistant to $\beta$-lactam antibiotics due to the presence of exported $\beta$-lactamases. The $\beta$-lactamases of M. tuberculosis (BlaC) and M. smegmatis (BlaS) are both proven Tatexported proteins that must be exported to protect against $\beta$-lactam antibiotics ${ }^{73}$.

In addition, M. tuberculosis Tat export has a role in pathogenesis, as some of the known Tatexported proteins of $M$. tuberculosis function in virulence (Table 2). For example, PlcB and PlcA are phospholipase $\mathrm{C}$ enzymes that are important for $M$. tuberculosis virulence ${ }^{86}$. $\mathrm{Rv} 2525 \mathrm{c}$ is another protein with a proven Tat signal peptide that has a role in $M$. tuberculosis virulence. However, in this case, the protein may act to limit pathogenesis, as an $r v 2525 c$ mutant demonstrates increased growth in macrophages and faster time to death in SCID mice ${ }^{60}$. Tat export systems do not exist in mammalian cells. This fact, combined with the importance of Tat export for viability, drug resistance, and virulence in $M$. tuberculosis, makes the Tat system a promising potential drug target (as reviewed in ${ }^{2}$ ).

\section{Model, Summary, and Future Questions}

While the mechanism of Tat export has not yet been directly investigated in mycobacteria, the requirement for Tat $\mathrm{A}, \mathrm{Tat} \mathrm{B}$, and TatC, and the presence of functional Tat signal peptides in Tat-exported mycobacterial proteins suggests that the Tat system of mycobacteria functions like the E. coli Tat system (Figure 2). In this case, Tat preproteins contain an Nterminal signal peptide with a twin arginine motif and fold in the cytoplasm prior to export. Tat-dependent preproteins then bind to the TatBC complex in the cytoplasmic membrane. Next, oligomers of TatA are recruited, likely forming the channel complex capable of accommodating folded proteins of varying size. In the presence of the proton motive force, preproteins are exported across the cytoplasmic membrane.

In the future, it will be important to study the mechanism of mycobacterial Tat export, and to confirm that it does indeed function as understood in other bacteria. Some Tat-dependent proteins in $E$. coli require chaperones to assist in their proper folding prior to export ${ }^{61}$; however, it is not known whether chaperones assist with Tat export in mycobacteria. Interestingly, the $M$. tuberculosis PlcB protein is exported by the Tat system of $M$. tuberculosis, but not by M. smegmatis ${ }^{64}$. This discrepancy could be explained by the existence of chaperones or other accessory Tat components present in M. tuberculosis but absent in M. smegmatis. Finally, our ability to predict $M$. tuberculosis Tat-dependent proteins is surprisingly unreliable. As Tat export becomes better understood and more $M$. tuberculosis Tat signal peptides are experimentally identified, Tat signal peptide prediction programs can be refined and more successfully applied to mycobacteria.

\section{ESX Export Systems}

\section{Introduction}

ESX export systems, which are also referred to as Type VII or WXG100 secretion systems, are specialized protein export systems originally identified in mycobacteria. Some Grampositive bacteria also possess ESX systems including Staphylococcus aureus, where the system is important to virulence ${ }^{87}$. The first ESX system identified was ESX-1 of $M$. tuberculosis, which is responsible for exporting the ESAT-6 protein (early secreted antigenic target $6 \mathrm{kD}$ ). The hallmark of ESX systems is that they export ESAT-6-like proteins; hence, the ESX name of these systems refers to ESAT-6. M. tuberculosis has five 
ESX systems (ESX-1-5) with various functions in mycobacterial physiology and/or virulence (Table 3 ).

All ESAT-6-like proteins are small ( 100 amino acids), possess a WXG amino acid motif, and notably lack a Sec or Tat signal peptide. In M. tuberculosis, each ESX system is encoded by a genomic locus of 7-18 genes that includes genes encoding core components of the ESX system and a pair of genes encoding exported ESAT-6-like proteins ${ }^{88}$. Progress in understanding ESX systems has come from studies in M. tuberculosis, M. smegmatis, and M. marinum. In our description below, we use the nomenclature recently introduced for ESX system components and exported proteins ${ }^{89}$. The ESX-2 and ESX-4 systems have not yet been studied; therefore, we limit our discussion below to the ESX-1, ESX-3, and ESX-5 systems.

\section{ESX-1}

Introduction-ESX-1 is the most thoroughly studied and best understood ESX system and it provides the model for how other systems likely function (for recent reviews of ESX-1 export, see ${ }^{90,91}$ ). Extensive mutant analysis has identified individual genes (both in and outside of the esx-1 locus) that are required for ESX-1 export ${ }^{92-96}$. Studies of $M$. tuberculosis mutants lacking a functional ESX-1 system also reveal the importance of this system to virulence $92,94,96-98$. Interestingly, the esx-1 genomic locus is located in the region of difference (RD1) that is present in M. tuberculosis but absent in the attenuated $M$. bovis $\mathrm{BCG}$ vaccine strain. The lack of ESX-1 in BCG explains the failure of BCG to express and secrete ESAT- 6 and it also helps explain the attenuated virulence of BCG $94,97,99$.

Exported Proteins and Targeting-Two ESAT-6-like proteins are exported by the ESX-1 system: the prototypical ESAT-6 protein and the ESAT-6-like protein CFP-10 (culture filtrate protein $10 \mathrm{kD}$ ). Both of these proteins are found exported to the cell wall of M. tuberculosis as well as secreted by M. tuberculosis 99,100 . ESAT-6 and CFP-10 are exported together as a 1:1 complex and each protein depends on the other for its export 98,101 . Additionally, neither protein has a Sec or Tat signal peptide. Instead, the CFP-10 protein has a seven amino acid targeting element at its C-terminus that directs export of the ESAT-6/CFP-10 complex via the ESX-1 system ${ }^{102}$.

In addition to small ESAT-6-like proteins, other larger proteins lacking classical N-terminal signal peptides are exported by ESX-1. One such protein is EspA. As with the codependence of ESAT-6 and CFP-10 for export, EspA export depends on the ESAT-6/ CFP-10 complex and, likewise, ESAT-6 and CFP-10 require EspA for their export 92, 95 . These co-dependent relationships suggest the need for these proteins to interact prior to export, and it raises the possibility that these exported proteins function in the export process itself. Other proteins exported by the M. tuberculosis ESX-1 system are EspC ${ }^{95}$, EspB ${ }^{103}$, and EspR ${ }^{104}$.

EspR is a particularly interesting ESX-1 exported protein because it is a transcriptional regulator of the espACD genes, which are required for ESAT-6 export. High cytoplasmic levels of EspR increase expression of espACD and, therefore, ESX-1 export. This results in more exported EspR and less EspR in the cytoplasm, which in turn reduces espACD expression ${ }^{104}$. In this way, EspR is part of a feedback loop for regulating the ESX-1 system.

System Components and Mechanism-From analyses of mutants lacking individual esx-1 genes, proteins necessary for ESX-1 export have been identified including predicted ATPases (EccA1 and EccCb1) and membrane proteins (EccB1, EccCa1, EccD1, EccE1, MycP1). 
EccA1 and EccCb1 are predicted cytosolic AAA ATPases that could provide energy for export through ATP hydrolysis. For EccA1, ATPase activity is demonstrated in vitro ${ }^{105}$, but for EccCb1 there is currently no demonstration of ATPase activity. Interestingly, both EccA1 and EccCb1 recognize C-terminal targeting sequences of ESX-1 exported proteins. EccA1 binds to the C-terminus of EspC that is required for EspC export ${ }^{106}$. EccCb1 recognizes the C-terminal targeting element of CFP-10 that is required for CFP-10/ESAT-6 export ${ }^{102}$.

Because of their probable cytoplasmic membrane location, the predicted membrane proteins required for ESX-1 export are candidates for being components of a channel or proteins that regulate or work with a channel. Of these proteins, EccD1 is a large protein with 10-11 predicted transmembrane domains and a compelling candidate for being a translocation channel component. Another predicted cytoplasmic membrane protein, EccCa1 interacts with the EccCb1 ATPase ${ }^{96}$. This protein interaction implies a role for EccCa1 in connecting protein targeting to the ESX-1 system (as carried out by EccCb1 recognition of the CFP-10 targeting element) with translocation across the cytoplasmic membrane. MycP1 is a predicted membrane protein with a serine protease domain located on the cell wall side of the membrane. While the absence of MycP1 abrogates ESX-1 export ${ }^{107}$, a mutant form of $\mathrm{MycP} 1$ with amino acid substitutions in the proteolytic active site actually has the opposite effect of increasing ESX-1 export ${ }^{108}$. Thus, it appears that MycP1 has multiple roles in ESX-1 export which remain to be resolved.

In the M. marinum ESX-1 system, immunofluoresence microscopy demonstrates that the EccCa1 homolog Mh3870 is localized at the cell pole, most often at the new pole ${ }^{109}$. Since EccCa1 is an important membrane component of the ESX-1 system (discussed above), this finding suggests that ESX-1 export occurs at new poles of the bacillus. Further studies are needed to discern if the ESX-1 system is similarly localized in M. tuberculosis and whether polar localization is necessary for ESX-1 secretion.

Contribution to Disease and Physiology—Research conducted in numerous laboratories clearly establishes a role for ESX-1 in M. tuberculosis virulence and, more specifically, a role promoting growth of $M$. tuberculosis in macrophages $93,96,97,108$. ESX-1 export is implicated in numerous $M$. tuberculosis processes with potential importance to pathogenesis. However, it remains to be clarified which ESX-1 effects are responsible for the role of this system in M. tuberculosis virulence. During macrophage infection, ESX-1 is important for the pathogen's ability to block phagosome maturation ${ }^{110}, 111$, limit host cytokine production ${ }^{96}$, and promote apoptosis of infected cells ${ }^{112}$. There is also data indicating the ESX-1 system promotes phagosome escape by $M$. tuberculosis 113 and host cell lysis that facilitates dissemination 93,94 . ESAT-6 can disrupt membranes, which may explain some of these effects $112,114,115$. Finally, in M. marinum the ESX-1 system recruits macrophages to nascent granulomas, promoting maturation of the granuloma and bacterial growth ${ }^{116}$.

Model, Summary, and Future Questions-While several components of the ESX-1 system are now known, the mechanism of ESX-1 export is not yet fully understood. A working model for the system is as follows (Figure 3). A C-terminal targeting element directs proteins, such as CFP-10, for ESX-1 export. Other proteins, such as ESAT-6, lack a targeting element and can form a complex with a protein like CFP-10 for targeting. By way of this C-terminal targeting element, proteins reach AAA ATPases EccA1 or EccCb1. These ATPases then interact with membrane components that may comprise or impact a membrane channel. EccD1 may be a component of the cytoplasmic membrane channel and ATP hydrolysis by the AAA ATPases may provide energy for the targeting and/or translocation events. 
In the future, it will be particularly important to investigate the process of ESX-1 export of proteins across the mycobacterial outer membrane. The model so far only addresses transport across the cytoplasmic membrane and the final steps of secretion remain a mystery. The issue of whether known ESX-1 exported proteins are part of the export system and/or have effector functions in virulence also requires attention. Finally, it is unlikely that all proteins exported by the ESX-1 pathway are known at this point. Discovering new substrates and elucidating their functions will help researchers better understand the ESX-1 system and its role in virulence. Since the ESX-1 system plays a role in M. tuberculosis virulence and is not found in eukaryotic cells, it has potential utility as a novel target for anti-tuberculosis drug development (reviewed in ${ }^{2}$ ).

\section{ESX-3}

Introduction-ESX-3 is essential in M. tuberculosis and appears important for iron and zinc uptake or homeostasis 117,118 . However, in comparison to ESX-1, ESX-3 has received less research attention and little is known about the mechanism of ESX-3 export.

Exported Proteins and Targeting / System Components and Mechanism-As is the case for all ESX systems, the ESX-3 locus encodes a pair of ESAT-6-like proteins. One of these proteins, EsxH, is shown to be secreted by the ESX-3 system of M. smegmatis, and its export is increased in low iron conditions ${ }^{118}$. At this point, no other ESX-3 components have been characterized.

Contribution to Disease and Physiology-The first clues for understanding the essential function of ESX-3 in M. tuberculosis came from the identification of the esx-3 gene locus as being regulated by the iron-dependent regulator IdeR ${ }^{119}$ and the zinc uptake regulator Zur ${ }^{120}$. Subsequently, it was shown that addition of extra iron or zinc can rescue the phenotype of esx-3 depletion in M. tuberculosis. Culture supernatant from wild-type $M$. tuberculosis can also rescue the esx-3 depletion phenotype. Taken together, these results suggest that ESX-3 secretes a product that is necessary for iron and zinc homeostasis or uptake ${ }^{117,}, 118$.

A completely different set of studies suggests a role for ESX-3 in eliciting protective immunity against $M$. tuberculosis. An M. smegmatis esx-3 mutant that is engineered to express the M. tuberculosis esx-3 genes, named IKEPLUS, elicits a robust immune response and better protective immunity against $M$. tuberculosis challenge than vaccination with $M$. bovis $\mathrm{BCG}$ in mice ${ }^{121}$. However, additional studies are required to understand the role of ESX-3 in this novel potential vaccine strain.

Model, Summary, and Future Questions-Our current understanding of the ESX-3 export system of mycobacteria is limited. The ESX-1 system may serve as a model for ESX-3 export, but this possibility remains to be evaluated. While the available data suggests that ESX-3 is responsible for iron and zinc homeostasis or uptake, the identification of ESX-3-exported proteins will be critical for understanding the role of this specialized export system in M. tuberculosis.

\section{ESX-5}

Introduction-After ESX-1, the next best-studied ESX system is ESX-5 (for a recent review see ${ }^{122}$ ). The distinguishing feature of ESX-5 is that it exports PE/PPE proteins that contain N-terminal Pro-Glu or Pro-Pro-Glu repeats ${ }^{123}$. The PE/PPE protein family is unique to mycobacteria. Some PE/PPE proteins are localized to the cell surface and are implicated in virulence and/or elicitation of host immune responses (for a review of PE/PPE proteins see ${ }^{124}$ ). At this point, ESX-5 has only been directly investigated in M. marinum and there 
are no published studies of $M$. tuberculosis mutants lacking esx-5. There are, however, reports of $M$. tuberculosis PE/PPE proteins that are exported in an ESX-5-dependent manner when expressed in $M$. marinum $123,125,126$. Thus, the potential exists for there being an equivalent ESX-5 system in M. tuberculosis.

Exported Proteins and Targeting-As expected for an ESX system, there is an ESAT-6-like protein secreted by the $M$. marinum ESX-5 system although the exact identity of this protein is not yet known ${ }^{123}$. The more notable feature of ESX-5 is that it secretes PE/ PPE proteins that lack Sec or Tat signal peptides. M. tuberculosis and other slow-growing mycobacteria possess a large number of these PE/PPE proteins, with almost $10 \%$ of the $M$. tuberculosis genome encoding for members of this protein family ${ }^{127}$. Comparative 2DPAGE analysis of proteins secreted by an esx-5 mutant or wild-type $M$. marinum identified eight PE/PPE proteins that depend on ESX-5 for export.

LipY is one of the PE/PPE proteins known to be exported by the ESX-5 system of $M$. marinum ${ }^{126}$. M. tuberculosis LipY has a PE domain at its $\mathrm{N}$-terminus while $M$. marinum LipY has a PPE domain at its N-terminus. LipY has a lipase domain at its C-terminus and is a demonstrated triacylglycerol hydrolase making it the only PE/PPE protein with a confirmed function ${ }^{128}$. Interestingly, in one study the PE/PPE domain of LipY is cleaved upon export and this domain is necessary for LipY export, suggesting it may function as a targeting element for the ESX-5 system ${ }^{126}$. However, this data is in conflict with another study that shows the PE/PPE domain of LipY is not needed for export when the protein is expressed in M. bovis $\mathrm{BCG}^{129}$.

As mentioned above, an esx-5 mutant of $M$. tuberculosis has yet to be investigated. However, select $M$. tuberculosis PE/PPE proteins (PPE13, PPE41, PPE10, PE_PGRS45, LipY) are exported to the bacterial cell surface or fully secreted in an ESX-5 dependent fashion when they are expressed in M. marinum $123,125,126$.

System Components and Mechanism-Because M. smegmatis lacks an ESX-5 system, it can be used as a mycobacterial host for reconstituting ESX-5 export. When the entire $M$. marinum esx-5 locus is introduced into $M$. smegmatis it functions to secrete the $M$. tuberculosis PPE41 protein that is co-expressed in these experiments ${ }^{125}$. At this point, there has been no study of the requirement or function of individual ESX-5 components, but this M. smegmatis system should prove useful for such analysis.

Contribution to Disease and Physiology-In M. marinum, the ESX-5 system is implicated in modulating innate immune responses of macrophages and in facilitating $M$. marinum dissemination from infected macrophages ${ }^{125,130}$. In M. tuberculosis, however, there are no studies linking ESX-5 to virulence and the system is not predicted by whole genome mutagenesis studies to be important for virulence ${ }^{131,132}$.

Model, Summary, and Future Questions-At least for M. marinum, it seems that ESX-5 is required for exporting a number of PE/PPE proteins. While the mechanistic details of ESX-5 export remain to be studied, our current knowledge of the ESX-1 system may be a useful starting point for understanding this system. It should be noted, however, that there is no evidence for ESX-1 exporting PE/PPE proteins which makes it possible that significant differences exist between systems. A major question to be resolved is whether the PE/PPE domain is required for export and serves as a targeting signal for the ESX-5 system 126, 129 . In the future, it will also be important to study the ESX-5 system directly in M. tuberculosis and determine if it is functional and important for virulence. 


\section{Conclusion}

M. tuberculosis has multiple ways to export proteins. In addition to the well known Sec and Tat systems, M. tuberculosis possesses specialized SecA2 and ESX protein export systems, and likely other systems as well. Continued study of mycobacterial protein export will be important to fully understand the mechanisms of export and the roles each system plays in pathogenesis. All of the currently known M. tuberculosis protein export systems are important in some way to bacterial viability and/or virulence. As such, any of these systems could prove useful as targets for future drug development to combat tuberculosis.

\section{Acknowledgments}

The authors would like to thank members of the Braunstein laboratory for critical reading of this manuscript. This work was supported by NIH AI054540.

\section{References}

1. WHO/HTM/TB2010.7 Pn. WHO Report 2010: Global Tuberculosis Control. Geneva, Switzerland: WHO Press; 2010.

2. Feltcher ME, Sullivan JT, Braunstein M. Protein export systems of Mycobacterium tuberculosis: novel targets for drug development? Future Microbiol. 2010; 5:1581-1597.10.2217/fmb.10.112 [PubMed: 21073315]

3. Moir DT, Di M, Wong E, Moore RA, Schweizer HP, Woods DE, Bowlin TL. Development and application of a cellular, gain-of-signal, bioluminescent reporter screen for inhibitors of type II secretion in Pseudomonas aeruginosa and Burkholderia pseudomallei. J Biomol Screen. 2011; 16:694-705.10.1177/1087057111408605 [PubMed: 21602485]

4. Swietnicki W, Carmany D, Retford M, Guelta M, Dorsey R, Bozue J, Lee MS, Olson MA. Identification of small-molecule inhibitors of Yersinia pestis Type III secretion system YscN ATPase. PLoS One. 2011; 6:e19716.10.1371/journal.pone.0019716 [PubMed: 21611119]

5. Paschos A, den Hartigh A, Smith MA, Atluri VL, Sivanesan D, Tsolis RM, Baron C. An in vivo high-throughput screening approach targeting the type IV secretion system component VirB8 identified inhibitors of Brucella abortus 2308 proliferation. Infect Immun. 2011; 79:10331043.10.1128/IAI.00993-10 [PubMed: 21173315]

6. Segers K, Anne J. Traffic jam at the bacterial sec translocase: targeting the SecA nanomotor by small-molecule inhibitors. Chem Biol. 2011; 18:685-698.10.1016/j.chembiol.2011.04.007 [PubMed: 21700205]

7. Finlay BB, Falkow S. Common themes in microbial pathogenicity revisited. Microbiol Mol Biol Rev. 1997; 61:136-169. [PubMed: 9184008]

8. Papanikou E, Karamanou S, Economou A. Bacterial protein secretion through the translocase nanomachine. Nat Rev Microbiol. 2007; 5:839-851.10.1038/nrmicro1771 [PubMed: 17938627]

9. Driessen AJ, Nouwen N. Protein translocation across the bacterial cytoplasmic membrane. Annu Rev Biochem. 2008; 77:643-667.10.1146/annurev.biochem.77.061606.160747 [PubMed: 18078384]

10. Braun, V.; Wu, HC. Lipoproteins, structure, function, biosynthesis and models for protein export. In: Ghuysen, JM.; Hackenbeck, R., editors. Bacterial cell wall. Amsterdam; New York: Elsevier; 1994. p. 319-342.

11. Yu NY, Wagner JR, Laird MR, Melli G, Rey S, Lo R, Dao P, Sahinalp SC, Ester M, Foster LJ, Brinkman FS. PSORTb 3.0: improved protein subcellular localization prediction with refined localization subcategories and predictive capabilities for all prokaryotes. Bioinformatics. 2010; 26:1608-1615.10.1093/bioinformatics/btq249 [PubMed: 20472543]

12. Bendtsen JD, Nielsen H, von Heijne G, Brunak S. Improved prediction of signal peptides: SignalP 3.0. J Mol Biol. 2004; 340:783-795.10.1016/j.jmb.2004.05.028 [PubMed: 15223320] 
13. Juncker AS, Willenbrock H, Von Heijne G, Brunak S, Nielsen H, Krogh A. Prediction of lipoprotein signal peptides in Gram-negative bacteria. Protein Sci. 2003; 12:1652-1662.10.1110/ ps.0303703 [PubMed: 12876315]

14. van der Sluis EO, Driessen AJ. Stepwise evolution of the Sec machinery in Proteobacteria. Trends Microbiol. 2006; 14:105-108.10.1016/j.tim.2006.01.009 [PubMed: 16490356]

15. Bordes P, Cirinesi AM, Ummels R, Sala A, Sakr S, Bitter W, Genevaux P. SecB-like chaperone controls a toxin-antitoxin stress-responsive system in Mycobacterium tuberculosis. Proc Natl Acad Sci U S A. 2011; 108:8438-8443.10.1073/pnas.1101189108 [PubMed: 21536872]

16. Cunningham K, Wickner W. Specific recognition of the leader region of precursor proteins is required for the activation of translocation ATPase of Escherichia coli. Proc Natl Acad Sci U S A. 1989; 86:8630-8634. [PubMed: 2554321]

17. Lill R, Dowhan W, Wickner W. The ATPase activity of SecA is regulated by acidic phospholipids, SecY, and the leader and mature domains of precursor proteins. Cell. 1990; 60:271-280. [PubMed: 2153463]

18. van der Wolk JP, de Wit JG, Driessen AJ. The catalytic cycle of the escherichia coli SecA ATPase comprises two distinct preprotein translocation events. EMBO J. 1997; 16:7297-7304.10.1093/ emboj/16.24.7297 [PubMed: 9405359]

19. Schiebel E, Driessen AJ, Hartl FU, Wickner W. Delta mu H+ and ATP function at different steps of the catalytic cycle of preprotein translocase. Cell. 1991; 64:927-939. [PubMed: 1825804]

20. Sassetti CM, Boyd DH, Rubin EJ. Genes required for mycobacterial growth defined by high density mutagenesis. Mol Microbiol. 2003; 48:77-84. [PubMed: 12657046]

21. Griffin JE, Gawronski JD, Dejesus MA, Ioerger TR, Akerley BJ, Sassetti CM. High-resolution phenotypic profiling defines genes essential for mycobacterial growth and cholesterol catabolism. PLoS Pathog. 2011; 7:e1002251.10.1371/journal.ppat.1002251 [PubMed: 21980284]

22. Braunstein M, Brown AM, Kurtz S, Jacobs WR Jr. Two nonredundant SecA homologues function in mycobacteria. J Bacteriol. 2001; 183:6979-6990.10.1128/JB.183.24.6979-6990.2001 [PubMed: 11717254]

23. Guo XV, Monteleone M, Klotzsche M, Kamionka A, Hillen W, Braunstein M, Ehrt S, Schnappinger D. Silencing Mycobacterium smegmatis by using tetracycline repressors. J Bacteriol. 2007; 189:4614-4623.10.1128/JB.00216-07 [PubMed: 17483222]

24. Rigel NW, Gibbons HS, McCann JR, McDonough JA, Kurtz S, Braunstein M. The Accessory SecA2 System of Mycobacteria Requires ATP Binding and the Canonical SecA1. J Biol Chem. 2009; 284:9927-9936.10.1074/jbc.M900325200 [PubMed: 19240020]

25. Hou JM, D’Lima NG, Rigel NW, Gibbons HS, McCann JR, Braunstein M, Teschke CM. ATPase activity of Mycobacterium tuberculosis SecA1 and SecA2 proteins and its importance for SecA2 function in macrophages. J Bacteriol. 2008; 190:4880-4887.10.1128/JB.00412-08 [PubMed: 18487341]

26. Sharma V, Arockiasamy A, Ronning DR, Savva CG, Holzenburg A, Braunstein M, Jacobs WR Jr, Sacchettini JC. Crystal structure of Mycobacterium tuberculosis SecA, a preprotein translocating ATPase. Proc Natl Acad Sci U S A. 2003; 100:2243-2248.10.1073/pnas.0538077100 [PubMed: 12606717]

27. Brundage L, Hendrick JP, Schiebel E, Driessen AJ, Wickner W. The purified E. coli integral membrane protein SecY/E is sufficient for reconstitution of SecA-dependent precursor protein translocation. Cell. 1990; 62:649-657. [PubMed: 2167176]

28. Hanada M, Nishiyama KI, Mizushima S, Tokuda H. Reconstitution of an efficient protein translocation machinery comprising SecA and the three membrane proteins, SecY, SecE, and SecG (p12). J Biol Chem. 1994; 269:23625-23631. [PubMed: 8089132]

29. Van den Berg B, Clemons WM Jr, Collinson I, Modis Y, Hartmann E, Harrison SC, Rapoport TA. X-ray structure of a protein-conducting channel. Nature. 2004; 427:36-44.10.1038/nature02218 [PubMed: 14661030]

30. Flower AM, Hines LL, Pfennig PL. SecG is an auxiliary component of the protein export apparatus of Escherichia coli. Mol Gen Genet. 2000; 263:131-136. [PubMed: 10732681] 
31. Duong F, Wickner W. Distinct catalytic roles of the SecYE, SecG and SecDFyajC subunits of preprotein translocase holoenzyme. EMBO J. 1997; 16:2756-2768.10.1093/emboj/16.10.2756 [PubMed: 9184221]

32. Paetzel M, Karla A, Strynadka NC, Dalbey RE. Signal peptidases. Chem Rev. 2002; 102:4549_ 4580. [PubMed: 12475201]

33. Sander P, Rezwan M, Walker B, Rampini SK, Kroppenstedt RM, Ehlers S, Keller C, Keeble JR, Hagemeier M, Colston MJ, Springer B, Bottger EC. Lipoprotein processing is required for virulence of Mycobacterium tuberculosis. Mol Microbiol. 2004; 52:1543-1552.10.1111/j. 1365-2958.2004.04041.x [PubMed: 15186407]

34. Facey SJ, Kuhn A. Biogenesis of bacterial inner-membrane proteins. Cell Mol Life Sci. 2010; 67:2343-2362.10.1007/s00018-010-0303-0 [PubMed: 20204450]

35. Egea PF, Stroud RM. Lateral opening of a translocon upon entry of protein suggests the mechanism of insertion into membranes. Proc Natl Acad Sci U S A. 2010; 107:1718217187.10.1073/pnas.1012556107 [PubMed: 20855604]

36. Dalbey RE, Kuhn A. YidC family members are involved in the membrane insertion, lateral integration, folding, and assembly of membrane proteins. J Cell Biol. 2004; 166:769-774.10.1083/ jcb.200405161 [PubMed: 15364957]

37. Dalbey RE, Chen M. Sec-translocase mediated membrane protein biogenesis. Biochim Biophys Acta. 2004; 1694:37-53.10.1016/j.bbamcr.2004.03.009 [PubMed: 15546656]

38. Sonnhammer EL, von Heijne G, Krogh A. A hidden Markov model for predicting transmembrane helices in protein sequences. Proc Int Conf Intell Syst Mol Biol. 1998; 6:175-182. [PubMed: 9783223]

39. McCann, JR.; Kurtz, S.; Braunstein, M. Secreted and Exported Proteins Important to Mycobacterium tuberculosis Pathogenesis. In: Wooldridge, K., editor. Bacterial secreted proteins : secretory mechanisms and role in pathogenesis. Wymondham: Caister Academic Press; 2009. p. 265-297.

40. McCann JR, McDonough JA, Sullivan JT, Feltcher ME, Braunstein M. Genome-wide identification of Mycobacterium tuberculosis exported proteins with roles in intracellular growth. $\mathrm{J}$ Bacteriol. 2011; 193:854-861.10.1128/JB.01271-10 [PubMed: 21148733]

41. Henao-Tamayo M, Junqueira-Kipnis AP, Ordway D, Gonzales-Juarrero M, Stewart GR, Young DB, Wilkinson RJ, Basaraba RJ, Orme IM. A mutant of Mycobacterium tuberculosis lacking the 19-kDa lipoprotein Rv3763 is highly attenuated in vivo but retains potent vaccinogenic properties. Vaccine. 2007; 25:7153-7159.10.1016/j.vaccine.2007.07.042 [PubMed: 17804126]

42. Sulzenbacher G, Canaan S, Bordat Y, Neyrolles O, Stadthagen G, Roig-Zamboni V, Rauzier J, Maurin D, Laval F, Daffe M, Cambillau C, Gicquel B, Bourne Y, Jackson M. LppX is a lipoprotein required for the translocation of phthiocerol dimycocerosates to the surface of Mycobacterium tuberculosis. EMBO J. 2006; 25:1436-1444.10.1038/sj.emboj.7601048 [PubMed: 16541102]

43. Bigi F, Gioffre A, Klepp L, Santangelo MP, Alito A, Caimi K, Meikle V, Zumarraga M, Taboga $\mathrm{O}$, Romano MI, Cataldi A. The knockout of the $\operatorname{lp} r G-R v 1410$ operon produces strong attenuation of Mycobacterium tuberculosis. Microbes Infect. 2004; 6:182-187.10.1016/j.micinf.2003.10.010 [PubMed: 14998516]

44. Owens MU, Swords WE, Schmidt MG, King CH, Quinn FD. Cloning, expression, and functional characterization of the Mycobacterium tuberculosis secA gene. FEMS Microbiol Lett. 2002; 211:133-141. [PubMed: 12076803]

45. Braunstein M, Espinosa BJ, Chan J, Belisle JT, Jacobs WR Jr. SecA2 functions in the secretion of superoxide dismutase A and in the virulence of Mycobacterium tuberculosis. Mol Microbiol. 2003; 48:453-464. [PubMed: 12675804]

46. Kurtz S, McKinnon KP, Runge MS, Ting JP, Braunstein M. The SecA2 secretion factor of Mycobacterium tuberculosis promotes growth in macrophages and inhibits the host immune response. Infect Immun. 2006; 74:6855-6864.10.1128/IAI.01022-06 [PubMed: 17030572]

47. Gibbons HS, Wolschendorf F, Abshire M, Niederweis M, Braunstein M. Identification of two Mycobacterium smegmatis lipoproteins exported by a SecA2-dependent pathway. J Bacteriol. 2007; 189:5090-5100.10.1128/JB.00163-07 [PubMed: 17496088] 
48. Hinchey J, Lee S, Jeon BY, Basaraba RJ, Venkataswamy MM, Chen B, Chan J, Braunstein M, Orme IM, Derrick SC, Morris SL, Jacobs WR Jr, Porcelli SA. Enhanced priming of adaptive immunity by a proapoptotic mutant of Mycobacterium tuberculosis. J Clin Invest. 2007; 117:2279-2288.10.1172/JCI31947 [PubMed: 17671656]

49. Rigel NW, Braunstein M. A new twist on an old pathway--accessory Sec [corrected] systems. Mol Microbiol. 2008; 69:291-302.10.1111/j.1365-2958.2008.06294.x [PubMed: 18544071]

50. Bensing BA, Sullam PM. An accessory sec locus of Streptococcus gordonii is required for export of the surface protein GspB and for normal levels of binding to human platelets. Mol Microbiol. 2002; 44:1081-1094. [PubMed: 12010500]

51. Chen Q, Wu H, Fives-Taylor PM. Investigating the role of secA2 in secretion and glycosylation of a fimbrial adhesin in Streptococcus parasanguis FW213. Mol Microbiol. 2004; 53:843856.10.1111/j.1365-2958.2004.04116.x [PubMed: 15255897]

52. Siboo IR, Chaffin DO, Rubens CE, Sullam PM. Characterization of the accessory Sec system of Staphylococcus aureus. J Bacteriol. 2008; 190:6188-6196.10.1128/JB.00300-08 [PubMed: 18621893]

53. Lenz LL, Mohammadi S, Geissler A, Portnoy DA. SecA2-dependent secretion of autolytic enzymes promotes Listeria monocytogenes pathogenesis. Proc Natl Acad Sci U S A. 2003; 100:12432-12437.10.1073/pnas.2133653100 [PubMed: 14527997]

54. Archambaud C, Nahori MA, Pizarro-Cerda J, Cossart P, Dussurget O. Control of Listeria superoxide dismutase by phosphorylation. J Biol Chem. 2006; 281:31812-31822.10.1074/ jbc.M606249200 [PubMed: 16905535]

55. Breukink E, Nouwen N, van Raalte A, Mizushima S, Tommassen J, de Kruijff B. The C terminus of SecA is involved in both lipid binding and SecB binding. J Biol Chem. 1995; 270:7902-7907. [PubMed: 7713885]

56. Fekkes P, van der Does C, Driessen AJ. The molecular chaperone SecB is released from the carboxy-terminus of SecA during initiation of precursor protein translocation. EMBO J. 1997; 16:6105-6113.10.1093/emboj/16.20.6105 [PubMed: 9321390]

57. Dempsey BR, Wrona M, Moulin JM, Gloor GB, Jalilehvand F, Lajoie G, Shaw GS, Shilton BH. Solution NMR structure and X-ray absorption analysis of the C-terminal zinc-binding domain of the SecA ATPase. Biochemistry. 2004; 43:9361-9371.10.1021/bi0493057 [PubMed: 15260479]

58. Dilks K, Rose RW, Hartmann E, Pohlschroder M. Prokaryotic utilization of the twin-arginine translocation pathway: a genomic survey. J Bacteriol. 2003; 185:1478-1483. [PubMed: 12562823]

59. De Buck E, Lammertyn E, Anne J. The importance of the twin-arginine translocation pathway for bacterial virulence. Trends Microbiol. 2008; 16:442-453.10.1016/j.tim.2008.06.004 [PubMed: 18715784]

60. Saint-Joanis B, Demangel C, Jackson M, Brodin P, Marsollier L, Boshoff H, Cole ST. Inactivation of Rv2525c, a substrate of the twin arginine translocation (Tat) system of Mycobacterium tuberculosis, increases beta-lactam susceptibility and virulence. J Bacteriol. 2006; 188:66696679.10.1128/JB.00631-06 [PubMed: 16952959]

61. Robinson C, Matos CF, Beck D, Ren C, Lawrence J, Vasisht N, Mendel S. Transport and proofreading of proteins by the twin-arginine translocation (Tat) system in bacteria. Biochim Biophys Acta. 2011; 1808:876-884.10.1016/j.bbamem.2010.11.023 [PubMed: 21126506]

62. Berks BC. A common export pathway for proteins binding complex redox cofactors? Mol Microbiol. 1996; 22:393-404. [PubMed: 8939424]

63. Marrichi M, Camacho L, Russell DG, DeLisa MP. Genetic toggling of alkaline phosphatase folding reveals signal peptides for all major modes of transport across the inner membrane of bacteria. J Biol Chem. 2008; 283:35223-35235.10.1074/jbc.M802660200 [PubMed: 18819916]

64. McDonough JA, McCann JR, Tekippe EM, Silverman JS, Rigel NW, Braunstein M. Identification of functional Tat signal sequences in Mycobacterium tuberculosis proteins. J Bacteriol. 2008; 190:6428-6438.10.1128/JB.00749-08 [PubMed: 18658266]

65. Hinsley AP, Stanley NR, Palmer T, Berks BC. A naturally occurring bacterial Tat signal peptide lacking one of the 'invariant' arginine residues of the consensus targeting motif. FEBS Lett. 2001; 497:45-49. [PubMed: 11376660] 
66. Ignatova Z, Hornle C, Nurk A, Kasche V. Unusual signal peptide directs penicillin amidase from Escherichia coli to the Tat translocation machinery. Biochem Biophys Res Commun. 2002; 291:146-149.10.1006/bbrc.2002.6420 [PubMed: 11829474]

67. Stanley NR, Palmer T, Berks BC. The twin arginine consensus motif of Tat signal peptides is involved in Sec-independent protein targeting in Escherichia coli. J Biol Chem. 2000; 275:1159111596. [PubMed: 10766774]

68. DeLisa MP, Samuelson P, Palmer T, Georgiou G. Genetic analysis of the twin arginine translocator secretion pathway in bacteria. J Biol Chem. 2002; 277:29825-29831.10.1074/ jbc.M201956200 [PubMed: 12021272]

69. Rose RW, Bruser T, Kissinger JC, Pohlschroder M. Adaptation of protein secretion to extremely high-salt conditions by extensive use of the twin-arginine translocation pathway. Mol Microbiol. 2002; 45:943-950. [PubMed: 12180915]

70. Bendtsen JD, Nielsen H, Widdick D, Palmer T, Brunak S. Prediction of twin-arginine signal peptides. BMC Bioinformatics. 2005; 6:167.10.1186/1471-2105-6-167 [PubMed: 15992409]

71. Selengut JD, Haft DH, Davidsen T, Ganapathy A, Gwinn-Giglio M, Nelson WC, Richter AR, White O. TIGRFAMs and Genome Properties: tools for the assignment of molecular function and biological process in prokaryotic genomes. Nucleic Acids Res. 2007; 35:D260-264.10.1093/nar/ gkl1043 [PubMed: 17151080]

72. Bagos PG, Nikolaou EP, Liakopoulos TD, Tsirigos KD. Combined prediction of Tat and Sec signal peptides with hidden Markov models. Bioinformatics. 2010; 26:2811-2817.10.1093/ bioinformatics/btq530 [PubMed: 20847219]

73. McDonough JA, Hacker KE, Flores AR, Pavelka MS Jr, Braunstein M. The twin-arginine translocation pathway of Mycobacterium smegmatis is functional and required for the export of mycobacterial beta-lactamases. J Bacteriol. 2005; 187:7667-7679.10.1128/JB. 187.22.7667-7679.2005 [PubMed: 16267291]

74. DeLisa MP, Tullman D, Georgiou G. Folding quality control in the export of proteins by the bacterial twin-arginine translocation pathway. Proc Natl Acad Sci U S A. 2003; 100:61156120.10.1073/pnas.0937838100 [PubMed: 12721369]

75. Matos CF, Robinson C, Di Cola A. The Tat system proofreads FeS protein substrates and directly initiates the disposal of rejected molecules. EMBO J. 2008; 27:2055-2063.10.1038/emboj. 2008.132 [PubMed: 18615097]

76. Posey JE, Shinnick TM, Quinn FD. Characterization of the twin-arginine translocase secretion system of Mycobacterium smegmatis. J Bacteriol. 2006; 188:1332-1340.10.1128/JB. 188.4.1332-1340.2006 [PubMed: 16452415]

77. Behrendt J, Standar K, Lindenstrauss U, Bruser T. Topological studies on the twin-arginine translocase component TatC. FEMS Microbiol Lett. 2004; 234:303-308.10.1016/j.femsle. 2004.03.048 [PubMed: 15135537]

78. Tarry MJ, Schafer E, Chen S, Buchanan G, Greene NP, Lea SM, Palmer T, Saibil HR, Berks BC. Structural analysis of substrate binding by the TatBC component of the twin-arginine protein transport system. Proc Natl Acad Sci U S A. 2009; 106:13284-13289.10.1073/pnas.0901566106 [PubMed: 19666509]

79. Alami M, Luke I, Deitermann S, Eisner G, Koch HG, Brunner J, Muller M. Differential interactions between a twin-arginine signal peptide and its translocase in Escherichia coli. Mol Cell. 2003; 12:937-946. [PubMed: 14580344]

80. Oates J, Barrett CM, Barnett JP, Byrne KG, Bolhuis A, Robinson C. The Escherichia coli twinarginine translocation apparatus incorporates a distinct form of TatABC complex, spectrum of modular TatA complexes and minor TatAB complex. J Mol Biol. 2005; 346:295-305.10.1016/ j.jmb.2004.11.047 [PubMed: 15663945]

81. Gohlke U, Pullan L, McDevitt CA, Porcelli I, de Leeuw E, Palmer T, Saibil HR, Berks BC. The TatA component of the twin-arginine protein transport system forms channel complexes of variable diameter. Proc Natl Acad Sci U S A. 2005; 102:10482-10486.10.1073/pnas.0503558102 [PubMed: 16027357] 
82. Bageshwar UK, Musser SM. Two electrical potential-dependent steps are required for transport by the Escherichia coli Tat machinery. J Cell Biol. 2007; 179:87-99.10.1083/jcb.200702082 [PubMed: 17908913]

83. Luke I, Handford JI, Palmer T, Sargent F. Proteolytic processing of Escherichia coli twin-arginine signal peptides by LepB. Arch Microbiol. 2009; 191:919-925.10.1007/s00203-009-0516-5 [PubMed: 19809807]

84. Gimenez MI, Dilks K, Pohlschroder M. Haloferax volcanii twin-arginine translocation substates include secreted soluble, C-terminally anchored and lipoproteins. Mol Microbiol. 2007; 66:15971606.10.1111/j.1365-2958.2007.06034.x [PubMed: 18045386]

85. Pickering BS, Oresnik IJ. The twin arginine transport system appears to be essential for viability in Sinorhizobium meliloti. J Bacteriol. 2010; 192:5173-5180.10.1128/JB.00206-10 [PubMed: 20675496]

86. Raynaud C, Guilhot C, Rauzier J, Bordat Y, Pelicic V, Manganelli R, Smith I, Gicquel B, Jackson $\mathrm{M}$. Phospholipases $\mathrm{C}$ are involved in the virulence of Mycobacterium tuberculosis. Mol Microbiol. 2002; 45:203-217. [PubMed: 12100560]

87. Burts ML, Williams WA, DeBord K, Missiakas DM. EsxA and EsxB are secreted by an ESAT-6like system that is required for the pathogenesis of Staphylococcus aureus infections. Proc Natl Acad Sci U S A. 2005; 102:1169-1174.10.1073/pnas.0405620102 [PubMed: 15657139]

88. Gey Van Pittius NC, Gamieldien J, Hide W, Brown GD, Siezen RJ, Beyers AD. The ESAT-6 gene cluster of Mycobacterium tuberculosis and other high G+C Gram-positive bacteria. Genome Biol. 2001; 2 RESEARCH0044.

89. Bitter W, Houben EN, Bottai D, Brodin P, Brown EJ, Cox JS, Derbyshire K, Fortune SM, Gao LY, Liu J, Gey van Pittius NC, Pym AS, Rubin EJ, Sherman DR, Cole ST, Brosch R. Systematic genetic nomenclature for type VII secretion systems. PLoS Pathog. 2009; 5:e1000507.10.1371/ journal.ppat.1000507 [PubMed: 19876390]

90. Simeone R, Bottai D, Brosch R. ESX/type VII secretion systems and their role in host-pathogen interaction. Curr Opin Microbiol. 2009; 12:4-10.10.1016/j.mib.2008.11.003 [PubMed: 19155186]

91. Abdallah AM, Gey van Pittius NC, Champion PA, Cox J, Luirink J, Vandenbroucke-Grauls CM, Appelmelk BJ, Bitter W. Type VII secretion--mycobacteria show the way. Nat Rev Microbiol. 2007; 5:883-891.10.1038/nrmicro1773 [PubMed: 17922044]

92. Fortune SM, Jaeger A, Sarracino DA, Chase MR, Sassetti CM, Sherman DR, Bloom BR, Rubin EJ. Mutually dependent secretion of proteins required for mycobacterial virulence. Proc Natl Acad Sci U S A. 2005; 102:10676-10681.10.1073/pnas.0504922102 [PubMed: 16030141]

93. Guinn KM, Hickey MJ, Mathur SK, Zakel KL, Grotzke JE, Lewinsohn DM, Smith S, Sherman DR. Individual RD1-region genes are required for export of ESAT-6/CFP-10 and for virulence of Mycobacterium tuberculosis. Mol Microbiol. 2004; 51:359-370.10.1046/j. 1365-2958.2003.03844.x [PubMed: 14756778]

94. Hsu T, Hingley-Wilson SM, Chen B, Chen M, Dai AZ, Morin PM, Marks CB, Padiyar J, Goulding C, Gingery M, Eisenberg D, Russell RG, Derrick SC, Collins FM, Morris SL, King CH, Jacobs WR Jr. The primary mechanism of attenuation of bacillus Calmette-Guerin is a loss of secreted lytic function required for invasion of lung interstitial tissue. Proc Natl Acad Sci U S A. 2003; 100:12420-12425.10.1073/pnas.1635213100 [PubMed: 14557547]

95. MacGurn JA, Raghavan S, Stanley SA, Cox JS. A non-RD1 gene cluster is required for Snm secretion in Mycobacterium tuberculosis. Mol Microbiol. 2005; 57:1653-1663.10.1111/j. 1365-2958.2005.04800.x [PubMed: 16135231]

96. Stanley SA, Raghavan S, Hwang WW, Cox JS. Acute infection and macrophage subversion by Mycobacterium tuberculosis require a specialized secretion system. Proc Natl Acad Sci U S A. 2003; 100:13001-13006.10.1073/pnas.2235593100 [PubMed: 14557536]

97. Lewis KN, Liao R, Guinn KM, Hickey MJ, Smith S, Behr MA, Sherman DR. Deletion of RD1 from Mycobacterium tuberculosis mimics bacille Calmette-Guerin attenuation. J Infect Dis. 2003; 187:117-123.10.1086/345862 [PubMed: 12508154]

98. Brodin P, Majlessi L, Marsollier L, de Jonge MI, Bottai D, Demangel C, Hinds J, Neyrolles O, Butcher PD, Leclerc C, Cole ST, Brosch R. Dissection of ESAT-6 system 1 of Mycobacterium 
tuberculosis and impact on immunogenicity and virulence. Infect Immun. 2006; 74:8898.10.1128/IAI.74.1.88-98.2006 [PubMed: 16368961]

99. Pym AS, Brodin P, Brosch R, Huerre M, Cole ST. Loss of RD1 contributed to the attenuation of the live tuberculosis vaccines Mycobacterium bovis BCG and Mycobacterium microti. Mol Microbiol. 2002; 46:709-717. [PubMed: 12410828]

100. Sorensen AL, Nagai S, Houen G, Andersen P, Andersen AB. Purification and characterization of a low-molecular-mass T-cell antigen secreted by Mycobacterium tuberculosis. Infect Immun. 1995; 63:1710-1717. [PubMed: 7729876]

101. Renshaw PS, Panagiotidou P, Whelan A, Gordon SV, Hewinson RG, Williamson RA, Carr MD. Conclusive evidence that the major T-cell antigens of the Mycobacterium tuberculosis complex ESAT-6 and CFP-10 form a tight, 1:1 complex and characterization of the structural properties of ESAT-6, CFP-10, and the ESAT-6*CFP-10 complex. Implications for pathogenesis and virulence. J Biol Chem. 2002; 277:21598-21603.10.1074/jbc.M201625200 [PubMed: 11940590]

102. Champion PA, Stanley SA, Champion MM, Brown EJ, Cox JS. C-terminal signal sequence promotes virulence factor secretion in Mycobacterium tuberculosis. Science. 2006; 313:16321636.10.1126/science.1131167 [PubMed: 16973880]

103. McLaughlin B, Chon JS, MacGurn JA, Carlsson F, Cheng TL, Cox JS, Brown EJ. A mycobacterium ESX-1-secreted virulence factor with unique requirements for export. PLoS Pathog. 2007; 3:e105.10.1371/journal.ppat.0030105 [PubMed: 17676952]

104. Raghavan S, Manzanillo P, Chan K, Dovey C, Cox JS. Secreted transcription factor controls Mycobacterium tuberculosis virulence. Nature. 2008; 454:717-721.10.1038/nature07219 [PubMed: 18685700]

105. Luthra A, Mahmood A, Arora A, Ramachandran R. Characterization of Rv3868, an essential hypothetical protein of the ESX-1 secretion system in Mycobacterium tuberculosis. J Biol Chem. 2008; 283:36532-36541.10.1074/jbc.M807144200 [PubMed: 18974091]

106. DiGiuseppe Champion PA, Champion MM, Manzanillo P, Cox JS. ESX-1 secreted virulence factors are recognized by multiple cytosolic AAA ATPases in pathogenic mycobacteria. Mol Microbiol. 2009; 73:950-962.10.1111/j.1365-2958.2009.06821.x [PubMed: 19682254]

107. Dave JA, Gey van Pittius NC, Beyers AD, Ehlers MR, Brown GD. Mycosin-1, a subtilisin-like serine protease of Mycobacterium tuberculosis, is cell wall-associated and expressed during infection of macrophages. BMC Microbiol. 2002; 2:30. [PubMed: 12366866]

108. Ohol YM, Goetz DH, Chan K, Shiloh MU, Craik CS, Cox JS. Mycobacterium tuberculosis $\mathrm{MycP} 1$ protease plays a dual role in regulation of ESX-1 secretion and virulence. Cell Host Microbe. 2010; 7:210-220.10.1016/j.chom.2010.02.006 [PubMed: 20227664]

109. Carlsson F, Joshi SA, Rangell L, Brown EJ. Polar localization of virulence-related Esx-1 secretion in mycobacteria. PLoS Pathog. 2009; 5:e1000285.10.1371/journal.ppat.1000285 [PubMed: 19180234]

110. MacGurn JA, Cox JS. A genetic screen for Mycobacterium tuberculosis mutants defective for phagosome maturation arrest identifies components of the ESX-1 secretion system. Infect Immun. 2007; 75:2668-2678.10.1128/IAI.01872-06 [PubMed: 17353284]

111. Xu J, Laine O, Masciocchi M, Manoranjan J, Smith J, Du SJ, Edwards N, Zhu X, Fenselau C, Gao LY. A unique Mycobacterium ESX-1 protein co-secretes with CFP-10/ESAT-6 and is necessary for inhibiting phagosome maturation. Mol Microbiol. 2007; 66:787-800.10.1111/j. 1365-2958.2007.05959.x [PubMed: 17908204]

112. Derrick SC, Morris SL. The ESAT6 protein of Mycobacterium tuberculosis induces apoptosis of macrophages by activating caspase expression. Cell Microbiol. 2007; 9:1547-1555.10.1111/j. 1462-5822.2007.00892.x [PubMed: 17298391]

113. van der Wel N, Hava D, Houben D, Fluitsma D, van Zon M, Pierson J, Brenner M, Peters PJ. M. tuberculosis and M. leprae translocate from the phagolysosome to the cytosol in myeloid cells. Cell. 2007; 129:1287-1298.10.1016/j.cell.2007.05.059 [PubMed: 17604718]

114. Smith J, Manoranjan J, Pan M, Bohsali A, Xu J, Liu J, McDonald KL, Szyk A, LaRonde-LeBlanc N, Gao LY. Evidence for pore formation in host cell membranes by ESX-1-secreted ESAT-6 and its role in Mycobacterium marinum escape from the vacuole. Infect Immun. 2008; 76:54785487.10.1128/IAI.00614-08 [PubMed: 18852239] 
115. de Jonge MI, Pehau-Arnaudet G, Fretz MM, Romain F, Bottai D, Brodin P, Honore N, Marchal G, Jiskoot W, England P, Cole ST, Brosch R. ESAT-6 from Mycobacterium tuberculosis dissociates from its putative chaperone CFP-10 under acidic conditions and exhibits membranelysing activity. J Bacteriol. 2007; 189:6028-6034.10.1128/JB.00469-07 [PubMed: 17557817]

116. Volkman HE, Pozos TC, Zheng J, Davis JM, Rawls JF, Ramakrishnan L. Tuberculous granuloma induction via interaction of a bacterial secreted protein with host epithelium. Science. 2010; 327:466-469.10.1126/science.1179663 [PubMed: 20007864]

117. Serafini A, Boldrin F, Palu G, Manganelli R. Characterization of a Mycobacterium tuberculosis ESX-3 conditional mutant: essentiality and rescue by iron and zinc. J Bacteriol. 2009; 191:6340 6344.10.1128/JB.00756-09 [PubMed: 19684129]

118. Siegrist MS, Unnikrishnan M, McConnell MJ, Borowsky M, Cheng TY, Siddiqi N, Fortune SM, Moody DB, Rubin EJ. Mycobacterial Esx-3 is required for mycobactin-mediated iron acquisition. Proc Natl Acad Sci U S A. 2009; 106:18792-18797.10.1073/pnas.0900589106 [PubMed: 19846780]

119. Rodriguez GM, Voskuil MI, Gold B, Schoolnik GK, Smith I. ideR, An essential gene in mycobacterium tuberculosis: role of IdeR in iron-dependent gene expression, iron metabolism, and oxidative stress response. Infect Immun. 2002; 70:3371-3381. [PubMed: 12065475]

120. Maciag A, Dainese E, Rodriguez GM, Milano A, Provvedi R, Pasca MR, Smith I, Palu G, Riccardi G, Manganelli R. Global analysis of the Mycobacterium tuberculosis Zur (FurB) regulon. J Bacteriol. 2007; 189:730-740.10.1128/JB.01190-06 [PubMed: 17098899]

121. Sweeney KA, Dao DN, Goldberg MF, Hsu T, Venkataswamy MM, Henao-Tamayo M, Ordway D, Sellers RS, Jain P, Chen B, Chen M, Kim J, Lukose R, Chan J, Orme IM, Porcelli SA, Jacobs WR Jr. A recombinant Mycobacterium smegmatis induces potent bactericidal immunity against Mycobacterium tuberculosis. Nat Med. 2011; 17:1261-1268.10.1038/nm.2420 [PubMed: 21892180]

122. Bottai D, Brosch R. Mycobacterial PE, PPE and ESX clusters: novel insights into the secretion of these most unusual protein families. Mol Microbiol. 2009; 73:325-328.10.1111/j. 1365-2958.2009.06784.x [PubMed: 19602151]

123. Abdallah AM, Verboom T, Weerdenburg EM, Gey van Pittius NC, Mahasha PW, Jimenez C, Parra M, Cadieux N, Brennan MJ, Appelmelk BJ, Bitter W. PPE and PE_PGRS proteins of Mycobacterium marinum are transported via the type VII secretion system ESX-5. Mol Microbiol. 2009; 73:329-340.10.1111/j.1365-2958.2009.06783.x [PubMed: 19602152]

124. Sampson SL. Mycobacterial PE/PPE proteins at the host-pathogen interface. Clin Dev Immunol. 2011; 2011:497203.10.1155/2011/497203 [PubMed: 21318182]

125. Abdallah AM, Verboom T, Hannes F, Safi M, Strong M, Eisenberg D, Musters RJ, Vandenbroucke-Grauls CM, Appelmelk BJ, Luirink J, Bitter W. A specific secretion system mediates PPE41 transport in pathogenic mycobacteria. Mol Microbiol. 2006; 62:667679.10.1111/j.1365-2958.2006.05409.x [PubMed: 17076665]

126. Daleke MH, Cascioferro A, de Punder K, Ummels R, Abdallah AM, van der Wel N, Peters PJ, Luirink J, Manganelli R, Bitter W. Conserved Pro-Glu (PE) and Pro-Pro-Glu (PPE) protein domains target LipY lipases of pathogenic mycobacteria to the cell surface via the ESX-5 pathway. J Biol Chem. 2011; 286:19024-19034.10.1074/jbc.M110.204966 [PubMed: 21471225]

127. Cole ST, Brosch R, Parkhill J, Garnier T, Churcher C, Harris D, Gordon SV, Eiglmeier K, Gas S, Barry CE 3rd, Tekaia F, Badcock K, Basham D, Brown D, Chillingworth T, Connor R, Davies R, Devlin K, Feltwell T, Gentles S, Hamlin N, Holroyd S, Hornsby T, Jagels K, Krogh A, McLean J, Moule S, Murphy L, Oliver K, Osborne J, Quail MA, Rajandream MA, Rogers J, Rutter S, Seeger K, Skelton J, Squares R, Squares S, Sulston JE, Taylor K, Whitehead S, Barrell BG. Deciphering the biology of Mycobacterium tuberculosis from the complete genome sequence. Nature. 1998; 393:537-544.10.1038/31159 [PubMed: 9634230]

128. Deb C, Daniel J, Sirakova TD, Abomoelak B, Dubey VS, Kolattukudy PE. A novel lipase belonging to the hormone-sensitive lipase family induced under starvation to utilize stored triacylglycerol in Mycobacterium tuberculosis. J Biol Chem. 2006; 281:3866-3875.10.1074/ jbc.M505556200 [PubMed: 16354661]

129. Mishra KC, de Chastellier C, Narayana Y, Bifani P, Brown AK, Besra GS, Katoch VM, Joshi B, Balaji KN, Kremer L. Functional role of the PE domain and immunogenicity of the 
Mycobacterium tuberculosis triacylglycerol hydrolase LipY. Infect Immun. 2008; 76:127140.10.1128/IAI.00410-07 [PubMed: 17938218]

130. Abdallah AM, Savage ND, van Zon M, Wilson L, Vandenbroucke-Grauls CM, van der Wel NN, Ottenhoff TH, Bitter W. The ESX-5 secretion system of Mycobacterium marinum modulates the macrophage response. J Immunol. 2008; 181:7166-7175. [PubMed: 18981138]

131. Rengarajan J, Bloom BR, Rubin EJ. Genome-wide requirements for Mycobacterium tuberculosis adaptation and survival in macrophages. Proc Natl Acad Sci U S A. 2005; 102:83278332.10.1073/pnas.0503272102 [PubMed: 15928073]

132. Sassetti CM, Rubin EJ. Genetic requirements for mycobacterial survival during infection. Proc Natl Acad Sci U S A. 2003; 100:12989-12994.10.1073/pnas.2134250100 [PubMed: 14569030]

133. Murphy, CK.; Beckwith, J. Export of Proteins to the Cell Envelope in Escherichia coli. In: Neidhardt, FC., editor. Escherichia coli and Salmonella : cellular and molecular biology. Washington, D.C: ASM Press; 1996. p. 967-978.

134. Shiba K, Ito K, Yura T, Cerretti DP. A defined mutation in the protein export gene within the $s p c$ ribosomal protein operon of Escherichia coli: isolation and characterization of a new temperature-sensitive secY mutant. EMBO J. 1984; 3:631-635. [PubMed: 6370688]

135. Pogliano KJ, Beckwith J. Genetic and molecular characterization of the Escherichia coli secD operon and its products. J Bacteriol. 1994; 176:804-814. [PubMed: 7507921]

136. Phillips GJ, Silhavy TJ. The E. coli ffh gene is necessary for viability and efficient protein export. Nature. 1992; 359:744-746.10.1038/359744a0 [PubMed: 1331806]

137. Gill DR, Salmond GP. The identification of the Escherichia coli fts $Y$ gene product: an unusual protein. Mol Microbiol. 1990; 4:575-583. [PubMed: 2161989]

138. van Bloois E, Nagamori S, Koningstein G, Ullers RS, Preuss M, Oudega B, Harms N, Kaback HR, Herrmann JM, Luirink J. The Sec-independent function of Escherichia coli YidC is evolutionary-conserved and essential. J Biol Chem. 2005; 280:12996-13003.10.1074/ jbc.M414094200 [PubMed: 15671040]

139. Bogsch EG, Sargent F, Stanley NR, Berks BC, Robinson C, Palmer T. An essential component of a novel bacterial protein export system with homologues in plastids and mitochondria. J Biol Chem. 1998; 273:18003-18006. [PubMed: 9660752]

140. Sargent F, Bogsch EG, Stanley NR, Wexler M, Robinson C, Berks BC, Palmer T. Overlapping functions of components of a bacterial Sec-independent protein export pathway. EMBO J. 1998; 17:3640-3650.10.1093/emboj/17.13.3640 [PubMed: 9649434]

141. Sargent F, Stanley NR, Berks BC, Palmer T. Sec-independent protein translocation in Escherichia coli. A distinct and pivotal role for the TatB protein. J Biol Chem. 1999; 274:36073-36082. [PubMed: 10593889]

142. Jackson M, Raynaud C, Laneelle MA, Guilhot C, Laurent-Winter C, Ensergueix D, Gicquel B, Daffe M. Inactivation of the antigen $85 \mathrm{C}$ gene profoundly affects the mycolate content and alters the permeability of the Mycobacterium tuberculosis cell envelope. Mol Microbiol. 1999; 31:1573-1587. [PubMed: 10200974]

143. Flores AR, Parsons LM, Pavelka MS Jr. Genetic analysis of the beta-lactamases of Mycobacterium tuberculosis and Mycobacterium smegmatis and susceptibility to beta-lactam antibiotics. Microbiology. 2005; 151:521-532.10.1099/mic.0.27629-0 [PubMed: 15699201]

144. Armitige LY, Jagannath C, Wanger AR, Norris SJ. Disruption of the genes encoding antigen 85A and antigen 85B of Mycobacterium tuberculosis H37Rv: effect on growth in culture and in macrophages. Infect Immun. 2000; 68:767-778. [PubMed: 10639445]

145. Copenhaver RH, Sepulveda E, Armitige LY, Actor JK, Wanger A, Norris SJ, Hunter RL, Jagannath C. A mutant of Mycobacterium tuberculosis H37Rv that lacks expression of antigen $85 \mathrm{~A}$ is attenuated in mice but retains vaccinogenic potential. Infect Immun. 2004; 72:70847095.10.1128/IAI.72.12.7084-7095.2004 [PubMed: 15557632]

146. Lamichhane G, Tyagi S, Bishai WR. Designer arrays for defined mutant analysis to detect genes essential for survival of Mycobacterium tuberculosis in mouse lungs. Infect Immun. 2005; 73:2533-2540.10.1128/IAI.73.4.2533-2540.2005 [PubMed: 15784600] 
147. Volkman HE, Clay H, Beery D, Chang JC, Sherman DR, Ramakrishnan L. Tuberculous granuloma formation is enhanced by a mycobacterium virulence determinant. PLoS Biol. 2004; 2:e367.10.1371/journal.pbio.0020367 [PubMed: 15510227]

148. Converse SE, Cox JS. A protein secretion pathway critical for Mycobacterium tuberculosis virulence is conserved and functional in Mycobacterium smegmatis. J Bacteriol. 2005; 187:12381245.10.1128/JB.187.4.1238-1245.2005 [PubMed: 15687187]

149. Flint JL, Kowalski JC, Karnati PK, Derbyshire KM. The RD1 virulence locus of Mycobacterium tuberculosis regulates DNA transfer in Mycobacterium smegmatis. Proc Natl Acad Sci U S A. 2004; 101:12598-12603.10.1073/pnas.0404892101 [PubMed: 15314236] 
A. Housekeeping Sec export

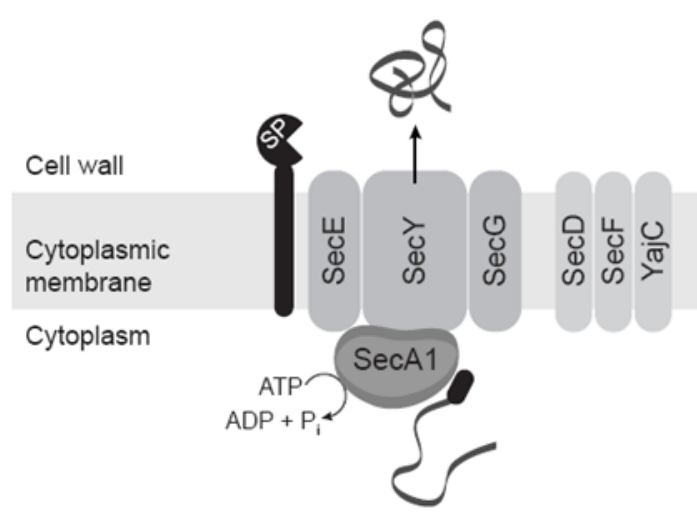

B. Accessory SecA2 export

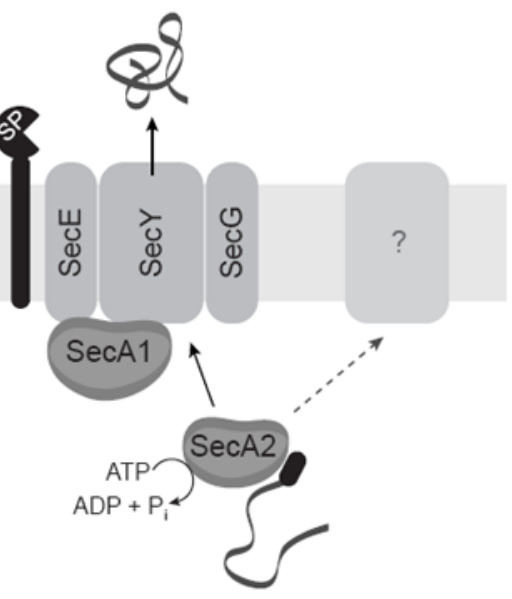

Figure 1. A model of the housekeeping Sec and accessory SecA2 export systems (A) Preproteins with $\mathrm{N}$-terminal signal peptides (black oval) are recognized by SecA1, which interacts with the SecYEG channel complex to form the translocase. SecA1 performs repeated cycles of ATP hydrolysis, pushing the unfolded preprotein through the SecYEG channel. SecD, SecF, and YajC increase efficiency of protein export. Signal peptides are removed by a LepB or LspA signal peptidase (SP), and mature proteins fold into their final conformations. (B) SecA2 recognizes a small subset of proteins and uses its ATPase activity to assist in their export. In the most likely scenario, SecA2 works with components of the housekeeping Sec export system and exports proteins across the cytoplasmic membrane through the SecYEG channel complex. However, it remains possible that other unknown components are required in addition to or in lieu of the housekeeping Sec components. The role of SecA2 in the export of proteins lacking signal peptides (not shown) is currently not understood. 


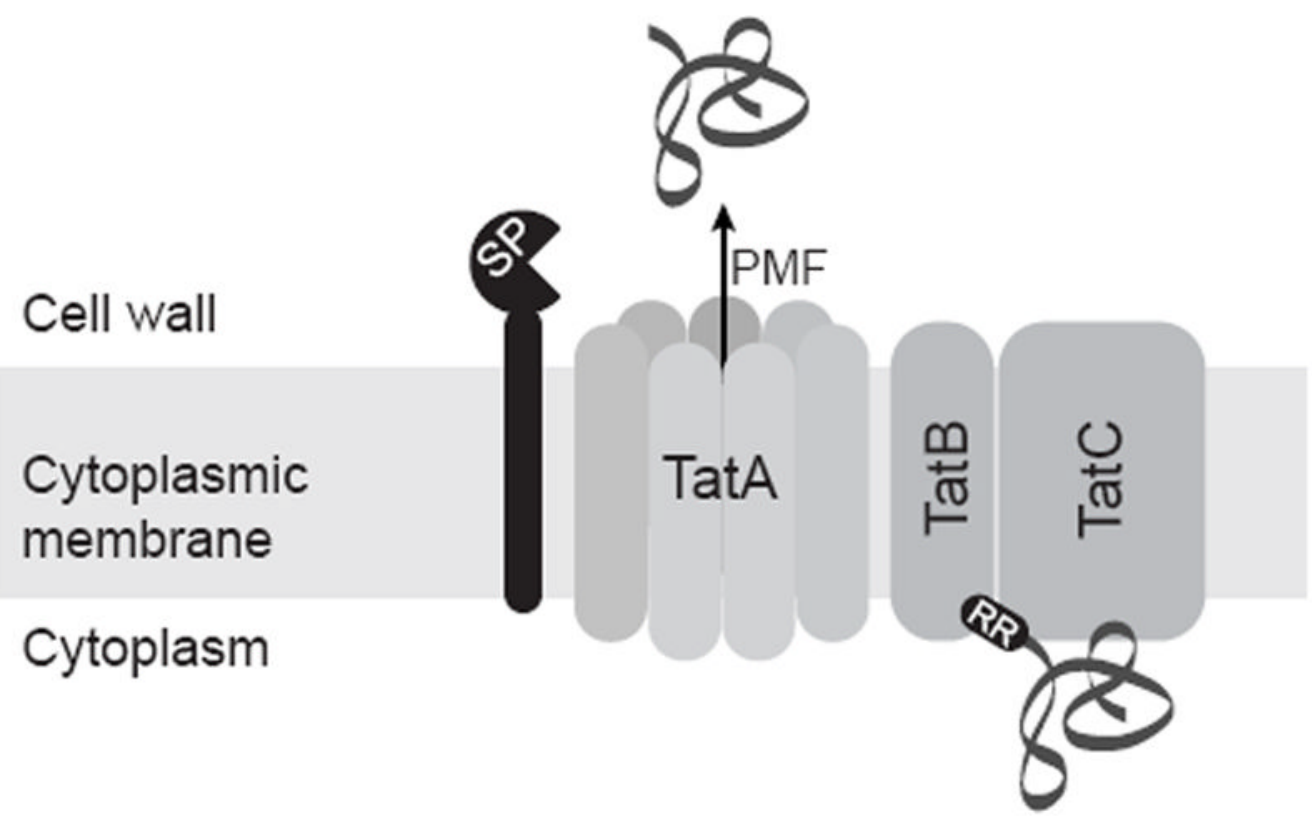

Figure 2. A model of the Tat export system

Tat preproteins contain an N-terminal signal peptide (black oval) with a twin arginine (RR) motif and fold in the cytoplasm prior to export. Tat-dependent preproteins then bind to the TatBC complex in the cytoplasmic membrane. Next, oligomers of TatA are recruited, likely forming the channel complex. In the presence of the proton motive force (PMF), preproteins are exported across the cytoplasmic membrane. Signal peptides are removed by a LepB or LspA signal peptidase (SP). 


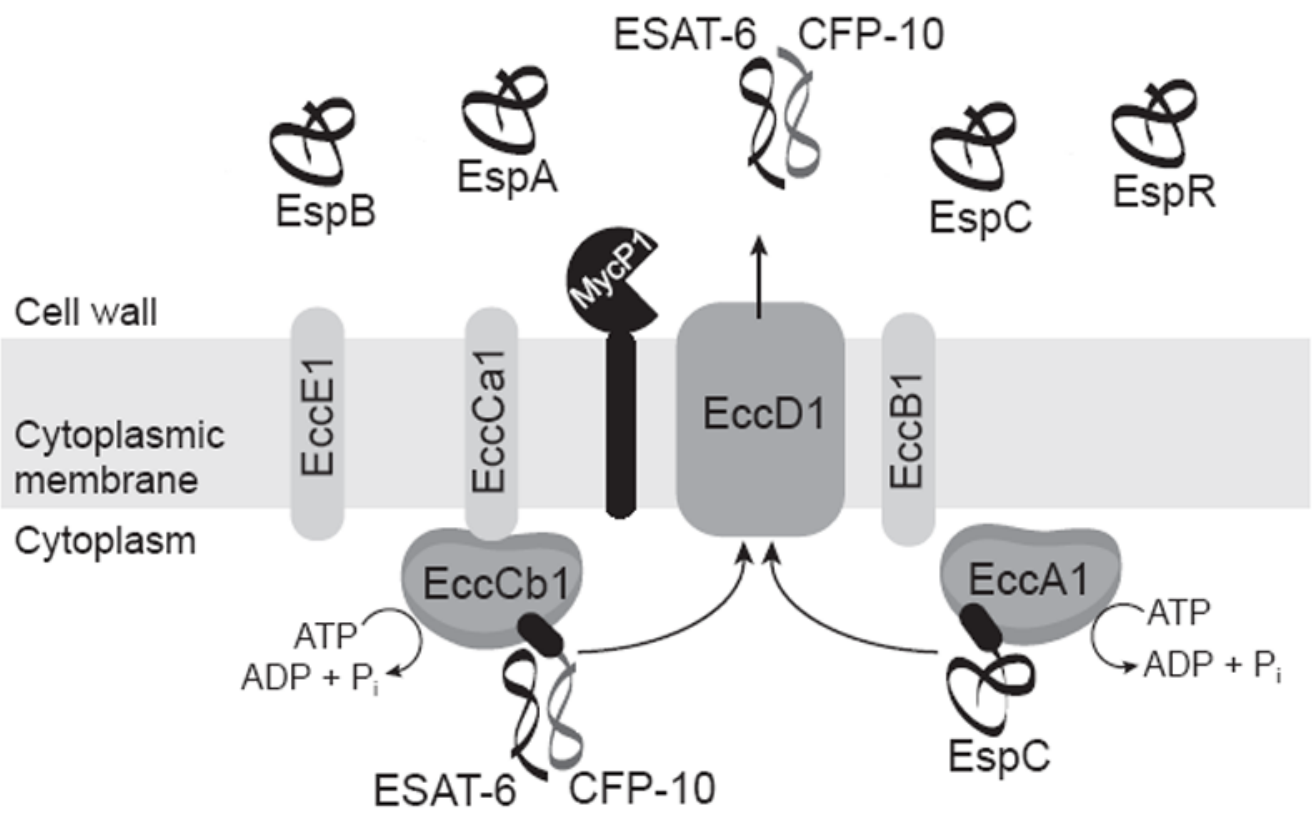

Figure 3. A model of the core components of the ESX-1 export system

ESX-1 exported proteins CFP-10 and EspC have a targeting element at their C-terminus (black ovals) that directs them to interact with cytosolic AAA ATPases EccCb1 and EccA1, respectively. Through interactions with cytoplasmic membrane proteins, these AAA ATPases are proposed to deliver proteins to an ESX-1 export channel. EccD1 is a leading candidate for being a component of this channel. ESAT-6 lacks a C-terminal targeting element and must form a complex with CFP-10 in order to be exported. The functions of EccE1, EccCa1, and EccB1 are unknown, but all are predicted cytoplasmic membrane proteins and core components of the ESX-1 pathway. MycP1 is a membrane protein with protease activity. Other proteins reported to be exported by the ESX-1 system and pictured here are EspA, EspB, and EspR. 
Table 1

M. tuberculosis homologs of conserved export system components.

\begin{tabular}{|c|c|c|c|}
\hline Export system components & Required for $E$. coli growth ${ }^{a}$ & M. tuberculosis homolog & Required for M. tuberculosis growth $b$ \\
\hline \multirow[t]{2}{*}{$\operatorname{Sec} A$} & \multirow[t]{2}{*}{ yes } & $\operatorname{Rv} 3240 c(\operatorname{Sec} A 1)$ & yes \\
\hline & & Rv1821 (SecA2) & no ${ }^{* \dagger} 45$ \\
\hline $\operatorname{Sec} \mathrm{Y}$ & yes & Rv0732 & yes \\
\hline SecE & yes & Rv0638 & yes \\
\hline SecG & no & Rv1440 & no \\
\hline SecD & no & Rv2587c & yes \\
\hline $\mathrm{SecF}$ & no & Rv2586c & yes \\
\hline YajC & no & Rv2588c & no \\
\hline SecB & no & $\operatorname{Rv} 1957^{+}$ & no \\
\hline Ffh (SRP) & yes & Rv2916c & yes \\
\hline FtsY & yes & Rv2921c & yes \\
\hline YidC & yes & Rv3921c & yes \\
\hline LepB & yes & Rv2903c & yes \\
\hline LspA & yes & Rv1539 & no*广33 \\
\hline TatA & no & Rv2094c & yes $^{*} 60$ \\
\hline TatB & no & Rv1224 & yes $^{*} 60$ \\
\hline TatC & no & Rv2093c & yes $* 6$ \\
\hline \multicolumn{4}{|c|}{$a_{\text {information compiled from references }} 133-141$} \\
\hline \multicolumn{4}{|c|}{$\begin{array}{l}b_{\text {unless marked by } * \text {, requirement for growth is predicted by deep sequencing of transposon libraries (Tn-seq) }} 21 \\
* \\
\text { experimentally demonstrated }\end{array}$} \\
\hline
\end{tabular}


Table 2

M. tuberculosis proteins containing functional Tat signal peptides.

\begin{tabular}{|c|c|c|c|}
\hline Protein & Description & $\begin{array}{l}\text { Required for } M \text {. } \\
\text { tuberculosis growth }\end{array}$ & $\begin{array}{l}\text { Required for } M \text {. } \\
\text { tuberculosis virulence } e\end{array}$ \\
\hline $\operatorname{Rv} 0063^{a}$ & Possible oxidoreductase & no & no \\
\hline $\mathrm{Rv} 0125^{b}(\mathrm{PepA})$ & Possible serine protease & no & no \\
\hline $\mathrm{Rv}_{0129 \mathrm{c}^{b}}(\mathrm{Ag} 85 \mathrm{C})$ & Mycolyl transferase; fibronectin-binding protein $\mathrm{C}$ & no ${ }^{*} 142$ & yes \\
\hline $\mathrm{Rv} 0132 \mathrm{c}^{c}(\mathrm{Fgd} 2)$ & Possible F420-dependent glucose-6-phosphate dehydrogenase & no & no \\
\hline $\operatorname{Rv} 0315^{a}$ & Possible $\beta$-1,3-glucanase precursor & no & no \\
\hline $\mathrm{Rv} 0483^{a}(\mathrm{LprQ})$ & Possible conserved lipoprotein & no & no \\
\hline $\mathrm{Rv} 0519 \mathrm{c}^{a}$ & Possible lipase & no & no \\
\hline $\mathrm{Rv}_{0774 \mathrm{c}^{a}}$ & Possible lipase; short-chain alcohol dehydrogenase family & no & no \\
\hline $\operatorname{Rv} 0846^{a}$ & Possible multicopper oxidase & no & no \\
\hline $\mathrm{Rv} 1860^{b}($ Apa $)$ & Glycosylated fibronectin-binding protein & no & no \\
\hline $\operatorname{Rv} 2041 c^{a}$ & Possible sugar-binding lipoprotein & no & no \\
\hline $\mathrm{Rv} 2068 \mathrm{c}^{a}(\mathrm{BlaC})$ & Class A $\beta$-lactamase & no $* 143$ & no \\
\hline $\mathrm{Rv} 2350 \mathrm{c}^{a}(\mathrm{PlcB})$ & Phospholipase C & no* 86 & yes ${ }^{*} 86$ \\
\hline $\operatorname{Rv} 2351 c^{a}(\mathrm{PlcA})$ & Phospholipase C & no ${ }^{*} 86$ & yes $^{*} 86$ \\
\hline $\operatorname{Rv} 2525 c^{a}$ & Conserved hypothetical protein & no $* 60$ & yes $* * 60$ \\
\hline $\mathrm{Rv} 2833 \mathrm{c}^{a}(\mathrm{UgpB})$ & Possible glycerol-3-phosphate-binding lipoprotein & no & no \\
\hline $\operatorname{Rv} 2843^{a}$ & Possible conserved transmembrane alanine-rich protein & no & no \\
\hline $\operatorname{Rv} 3804 c^{b}(\mathrm{Ag} 85 \mathrm{~A})$ & Mycolyl transferase; fibronectin-binding protein A & no ${ }^{*} 144$ & yes ${ }^{*} 144,145$ \\
\hline \multicolumn{4}{|l|}{$a_{\text {identified in }} 64$} \\
\hline \multicolumn{4}{|l|}{$b_{\text {identified in }} 63$} \\
\hline \multicolumn{4}{|c|}{$d_{\text {unless marked by }}^{*}$, requirement for growth is predicted by deep sequencing of transposon libraries (Tn-seq) 21} \\
\hline \multicolumn{4}{|c|}{$e_{\text {unless marked by }}^{*}$, requirement for virulence is predicted by Transposon Site Hybridization (TraSH) 131,132 or Designer Arrays for Defined } \\
\hline \multicolumn{4}{|c|}{ Mutant Analysis (DeADMAn) 146} \\
\hline * experimentally demo & strated & & \\
\hline
\end{tabular}


Table 3

Functions of ESX export systems in mycobacteria.

\begin{tabular}{|c|c|}
\hline System & Function \\
\hline ESX-1 & $\begin{array}{l}\text { virulence }\left(\text { M. tuberculosis }{ }^{92,94,96-98}\right)\left(\text { M. marinum }^{147}\right) \\
\text { conjugation }\left(\text { M. smegmatis }{ }^{148,149}\right)\end{array}$ \\
\hline ESX-2 & not studied \\
\hline ESX-3 & essential for viability $\left(\right.$ M. tuberculosis ${ }^{117}$ ) iron and zinc uptake or homeostasis $\left(\right.$ M. tuberculosis $\left.{ }^{117,} 118\right)$ \\
\hline ESX-4 & not studied \\
\hline ESX-5 & immune modulation $\left(\right.$ M. marinum $\left.{ }^{125,130}\right)$ \\
\hline
\end{tabular}

